\title{
Virus like particles as a platform for cancer vaccine development
}

\author{
Hui Kian Ong ${ }^{1}$, Wen Siang Tan ${ }^{2,3}$, Kok Lian Ho ${ }^{\text {corresp. } 1}$ \\ 1 Department of Pathology, Faculty of Medicine and Health Sciences, Universiti Putra Malaysia, Serdang, Selangor, Malaysia \\ 2 Department of Microbiology, Faculty of Biotechnology and Biomolecular Sciences, Universiti Putra Malaysia, Serdang, Selangor, Malaysia \\ 3 Institute of Bioscience, Universiti Putra Malaysia, Serdang, Selangor, Malaysia \\ Corresponding Author: Kok Lian Ho \\ Email address: klho@upm.edu.my
}

Cancers have killed millions of people in human history and are still posing a serious health problem worldwide. Therefore, there is an urgent need for developing preventive and therapeutic cancer vaccines. Among various cancer vaccine development platforms, viruslike particles (VLPS) offer several advantages. VLPs are multimeric nanostructures with morphology resembling that of native viruses and are mainly composed of surface structural proteins of viruses but are devoid of viral genetic material rendering them neither infective nor replicative. In addition, they can be engineered to display multiple highly ordered heterologous epitopes or peptides in order to optimize the antigenicity and immunogenicity of the displayed entities. Like native viruses, specific epitopes displayed on VLPs can be taken up, processed, and presented by antigen-presenting cells to elicit potent specific humoral and cell-mediated immune responses. Several studies also indicated that VLPS could overcome the immunosuppressive state of the tumor microenvironment and break self-tolerance to elicit strong cytotoxic lymphocyte activity, which is crucial for both virus clearance and destruction of cancerous cells. Collectively, these unique characteristics of VLPS make them optimal cancer vaccine candidates. This review discusses current progress in the development of VLP-based cancer vaccines and some potential drawbacks of VLPs in cancer vaccine development. Extracellular vesicles with close resembling to viral particles are also be discussed and compared with VLPS as a platform in cancer vaccine developments. 
1 Virus-like particles as a platform for cancer vaccine development

2 Hui Kian Ong ${ }^{1}$, Wen Siang Tan ${ }^{2,3}$, and Kok Lian $\mathrm{Ho}^{1 *}$

$3{ }^{1}$ Department of Pathology, Faculty of Medicine and Health Sciences, Universiti Putra Malaysia,

443400 UPM Serdang, Selangor, Malaysia.

$5 \quad{ }^{2}$ Department of Microbiology, Faculty of Biotechnology and Biomolecular Sciences, Universiti

6 Putra Malaysia, 43400 UPM Serdang, Selangor, Malaysia.

7 Institute of Bioscience, Universiti Putra Malaysia, 43400 UPM Serdang, Selangor, Malaysia.

8

$9 *$ Corresponding author

10 Email: klho@upm.edu.my

11 Tel: $+603-8947-2729$

12 Fax: +603-8941-2787

13

14 Running head: Virus-like particles in cancer vaccine development

15

16

17

18 


\section{Abstract}

22 Cancers have killed millions of people in human history and are still posing a serious health problem worldwide. Therefore, there is an urgent need for developing preventive and therapeutic cancer vaccines. Among various cancer vaccine development platforms, virus-like particles (VLPs) offer several advantages. VLPs are multimeric nanostructures with morphology resembling that of native viruses and are mainly composed of surface structural proteins of viruses but are devoid of viral genetic material rendering them neither infective nor replicative. In addition, they can be engineered to display multiple highly ordered heterologous epitopes or peptides in order to optimize the antigenicity and immunogenicity of the displayed entities. Like native viruses, specific epitopes displayed on VLPs can be taken up, processed, and presented by antigen-presenting cells to elicit potent specific humoral and cell-mediated immune responses. Several studies also indicated that VLPs could overcome the immunosuppressive state of the tumor microenvironment and break self-tolerance to elicit strong cytotoxic lymphocyte activity, which is crucial for both virus clearance and destruction of cancerous cells. Collectively, these unique characteristics of VLPs make them optimal cancer vaccine candidates. This review discusses current progress in the development of VLP-based cancer vaccines and some potential drawbacks of VLPs in cancer vaccine development. Extracellular vesicles with close resembling to viral particles are also be discussed and compared with VLPs as a platform in cancer vaccine developments. 


\subsection{Introduction}

46

47

Vaccination remains the most effective approach in the prevention and control of infectious diseases. Eradication of fatal smallpox virus in 1979 represented an extraordinary milestone in vaccinology (Strassburg 1982). Presently, the majority of commercial vaccines are formulated to fight infectious diseases, but cancer vaccines are rarely reported. Nevertheless, the idea of prospective cancer vaccination was suggested by Dr. William Coley who "vaccinated" cancer patients intratumorally with inactivated Streptococcus pyogenes and Serratia marcescens, which became known as Coley's Toxin in 1891 (McCarthy 2006). The rationale behind his attempt was prompted by his observation of sarcoma remission in patients who had developed erysipelas. Coley's Toxin was claimed to be an effective immunotherapeutic agent against cancer but unfortunately, the treatment was viewed as a scientific controversy at that time (Guo et al. 2013). Today, a better understanding of tumor immunology has proven the efficacy of Coley's Toxin. Moreover, improved strategies of vaccine design have allowed the development of many potential cancer vaccines over the past 60 years (Schlom 2012). However, the process of translation of experimental cancer vaccines into effective therapeutic agents for clinical use is often challenging. To date, licensed cancer vaccines are only available for liver, cervical, and prostate cancers (Cuzick 2015; Graff \& Chamberlain 2015; Kushnir et al. 2012; Ma et al. 2010).

According to the National Cancer Institute of the United States, cancer vaccines are biological response modifiers that stimulate or restore the function of the immune system to fight infections 
64 and diseases (Lollini et al. 2006). In general, cancer vaccines are categorized into i) preventive

65 cancer vaccines and ii) therapeutic cancer vaccines (Liu 2014). The former preparations, also

66 known as prophylactic vaccines, are effective against oncoviruses, such as hepatitis B virus

67 (HBV), hepatitis C virus (HCV), human papillomavirus (HPV), Epstein-Barr virus (EBV),

68 Kaposi's sarcoma-associated herpesvirus, human T-cell lymphotropic virus, and merkel cell

69 polyomavirus (Parkin 2006). Table 1 summarizes information about these oncoviruses and

70 diseases associated with them. By definition, administration of a preventive cancer vaccine

71 elicits immune responses of the host against the invasion of oncoviruses, whereas cancer

72 therapeutic vaccines are a form of immunotherapy that stimulates and enhances patient's own

73 immune system to fight against pre-existing cancers (Liu 2014). Compared to the current

74 conventional cancer treatments, which include invasive surgeries, chemotherapy, and

75 radiotherapy, immunotherapy approach is less invasive, has fewer detrimental side effects, and

76 can confer long-term cancer remission or even cancer immunity (Dimberu \& Leonhardt 2011).

77 Tumor-induced immunosuppression in tumor microenvironment (TME) is one of the primary

78 factors that impede the development of cancer vaccines (Wang et al. 2017). Several

79 immunosuppressive leukocytes, including myeloid derived suppressor cells (MDSCs), tumor

80 associated macrophages (TAMs) and regulatory T cells (Tregs) resident at the TME sites, release

81 immunosuppressive cytokines, such as TGF- $\beta$ and IL-10, which promote tumor growth,

82 metastasis, and angiogenesis (Cesana et al. 2006). TAMs also inhibit T-cell activation and trigger

83 apoptosis of activated T-cells, which greatly reduces the amount of tumor infiltrating

84 lymphocytes (Kuang et al. 2009; Williams et al. 2016). In addition, poorly immunogenic tumor

85 self-antigen also exhibits immunological tolerance that leads to ineffective counteracting

86 immune responses (Guo et al. 2013). Therefore, an effective cancer vaccine must be capable of 
87 eliciting strong antitumor immune responses to overcome TME immunosuppressive state and 88 break self-tolerance.

89 Successful vaccination relies heavily on the immunogenicity and presentation efficiency of the tumor antigen. Various entities have been employed to function as tumor antigen delivery 91 platforms. In this regard, virus-like particles (VLPs) offer several advantages over other 92 substances. VLPs are multimeric nanostructures morphologically resembling authentic viral particles. They are mainly composed of viral structural proteins with inherent self-assembly 94 properties but are devoid of viral genetic material (Chroboczek et al. 2014). Thus, VLPs are nonreplicative and non-infectious, which greatly enhances their safety (Noad \& Roy 2003).

96 In general, VLPs can be classified into non-enveloped and enveloped VLPs. The formers are 97 self-assembled from at least one viral protein which is expressed using a suitable host expression 98 system such as mammalian cells, insect cells, yeasts, bacteria and cell free systems without acquiring any host component (Kushnir et al. 2012). Yeasts and mammalian cells are the most commonly employed expression systems in the production of commercialized HBV and HPV VLP-based vaccines (Kushnir et al. 2012). However, production of more structurally complex non-enveloped chimeric VLPs involves the display of heterologous epitopes or peptides on the surface of VLPs via genetic engineering (Figure 1a) (Yong et al. 2015a; Yong et al. 2015b). Non-enveloped VLPs can also be chemically conjugated with a target antigen via heterobifunctional chemical linker such as sulfosuccinimidyl 4-(N-maleimidomethyl)cyclohexane-1carboxylate (sulfo-SMCC) and nanoglue, in which, the chimeric VLPs can be produced without extensive genetic alteration and this overcomes the limitation imposed on VLP formation (Figure 1b) (Biabanikhankahdani et al. 2016; Jemon et al. 2013; Lee et al. 2012). On the other hand, enveloped VLPs acquire part of the host cell membranes upon maturation as their lipid envelope, 
110 where a foreign epitope or peptide could be integrated and displayed on the surface (Gheysen et

111 al. 1989; Haynes 2009). Similar to non-enveloped VLPs, enveloped VLPs can be produced by

112 expressing several viral structural proteins in a suitable expression system. Alternatively, a

113 protein transfer technique can be employed to display the heterologous epitopes or peptides on

114 the surface of the enveloped VLPs. This approach allows spontaneous incorporation of the

115 glycosylphosphatidylinositol (GPI)-anchored protein or other immunostimulatory molecules to

116 the lipid bilayer of the enveloped VLPs via a simple incubation step (Figure 1c) (Patel et al.

117 2015a). The primary advantage of the protein transfer technology in the production of chimeric

118 enveloped VLP is its ability to retain the functionality of the incorporated protein without

119 extensive genetic modification (Shashidharamurthy et al. 2012). In addition, attributed to the

120 viral origin of VLPs, some of the VLP-based vaccines are self-adjuvating, in which, they contain

121 the pathogen associated molecular pattern (PAMP) of viruses that could potentially enhance the

122 activation of innate immune systems via the Toll-like receptors and pattern recognition receptors

123 (Crisci et al. 2012; Rynda-Apple et al. 2014). These self-assembling, engineerable, and safe

124 VLPs can be leveraged to display various tumor antigens for targeting different cancers (Patel et

125 al. 2015a; Patel et al. 2015b). Genetic fusion of a tumor antigen to a non-self-antigen, such as a

126 virus coat protein, was previously reported to notably improve its immunogenicity (Savelyeva et

127 al. 2001). Tumor self-antigens incorporated onto the surface of VLPs can be efficiently taken up,

128 processed, and presented by specialized dendritic cells (DCs). Figure 2 shows that priming of

$129 \mathrm{CD}^{+}$cytotoxic $\mathrm{T}$ lymphocytes (CTLs) and $\mathrm{CD}^{+} \mathrm{T}$ helper cells by activated DCs elicits potent

130 antitumor immune responses and breaks self-tolerance (Barth et al. 2005; Guo et al. 2013; Li et

131 al. 2013). Furthermore, VLPs displaying a tumor antigen (VLP-DTA) do not contain auto-

132 antigens, thus they offer an alternative scaffold with a much lower risk of autoimmunity in 
133 relative to the whole tumor antigen vaccines which present the entire spectrum of potential tumor

134 antigens, including auto-antigen to DC (Schirrmacher \& Fournier 2010). Several studies also

135 indicated that VLPs could overcome the immunosuppressive state of the TME characterized by a

136 significant decrease in immunosuppressive leukocyte population and levels of corresponding

137 cytokines in immunized animals (Cubas et al. 2011; Li et al. 2008).

138 The ultimate objective of a cancer vaccine is to produce cell-mediated immune responses, 139 specifically Th1 immune responses, for efficient activation of CD8 ${ }^{+} \mathrm{T}$-cells or CTLs, which are 140 critical for both the clearance of infected cells and destruction of cancerous cells (Maecker et al. 141 1998). The capability of VLP-DTA to selectively elicit strong cell-mediated and humoral 142 immunities against tumor cells while reducing the risk of autoimmunity makes it an ideal 143 candidate for cancer vaccine delivery platform (Jennings \& Bachmann 2008). This review 144 discusses current progress in the development of VLP-based cancer vaccines against i) 145 hepatocellular carcinoma, ii) cervical cancer, iii) pancreatic cancer, iv) prostate cancer, v) breast 146 cancer, vi) skin cancer, vii) lung cancer, and viii) oncovirus-associated cancers (see Table 2).

\subsection{Survey Methodology}

In this study, we reviewed articles related to VLP-based cancer vaccines. All references in this review paper were retrieved using search engines such as PubMed, Scopus, Google Scholar and ResearchGate. Keywords such as Virus-like particles, cancer vaccines, cytotoxic lymphocyte,

152 tumor antigen and oncovirus were used to search for the references. 
155 Primary liver cancers are ranked as the third leading cause of cancer-related mortality in the 156 world (Altekruse et al. 2014). The 5-year relative survival rate of liver cancer patients is 157 estimated to be $25-45 \%$ (Kim et al. 2014). Approximately one third of the world population are 158 infected with HBV, whereas about 350 million people worldwide developed chronic infection 159 (Lavanchy 2005). In the United States, around 50\% of liver cancers are caused by HBV and 160 HCV (Ly et al. 2012). Despite the presence of effective HBV preventive vaccines, low 161 accessibility to such vaccines in resource-limited countries and the lack of therapeutic vaccines 162 have retarded the eradication of HBV. Liver cancer caused by HCV infection, however, is 163 expected to increase in the following decades unless preventive HCV vaccines become 164 universally available. To effectively reduce the incidence of oncovirus-associated liver cancers, 165 vaccinations with cancer preventive vaccines against $\mathrm{HBV}$ and HCV are essential, and 166 continuing development of therapeutic vaccines is required to treat patients with pre-existing 167 infection.

168 Since the invention of the first licensed HBV vaccine, tremendous amount of effort has been 169 applied to the development of optimized HBV vaccines. To date, there are 12 VLP-based HBV 170 vaccines on the market. Typical examples include Engerix-B, Enivac HB, Gene Vac-B, 171 Hepavax-Gene, and Recombivax HB. All commercial VLP-based HBV vaccines are produced 172 by expressing hepatitis B virus surface antigen (HBsAg) in yeasts or mammalian expression 173 systems (Kushnir et al. 2012). In an attempt to improve efficacy of current vaccines, Pleckaityte 174 et al. (2015) innovatively incorporated heterologous HBsAg specific single-chain fragment 175 variable into VLPs of hamster polyomavirus. In vitro virus neutralization assay demonstrated 176 promising antiviral activity of the vaccine, but its protective efficacy has yet to be investigated in 177 vivo. This vaccine is believed to be a potential therapeutic HBV vaccine which could provide 
178 curative effects to chronic HBV patients (Pleckaityte et al. 2015). Recently, Macrobrachium

179 rosenbergii nodavirus $(M r \mathrm{NV})$ VLPs were employed to display an HBV antigenic determinant

180 known as the " $a$ " determinant (Yong et al. 2015a), an immunodominant region responsible for

181 the induction of HBV-specific humoral immune responses (Howard \& Allison 1995; Ruiz-

182 Tachiquin et al. 2007). Immunization of mice with $M r \mathrm{NV}$ chimeric VLPs induced the production

183 of " $a$ " determinant-specific antibodies and, surprisingly, the induced antibody levels were

184 significantly higher than those observed after the administration of the commercial HBV vaccine

185 Engerix-B, which served as a positive control in that study (Yong et al. 2015a).

186 With respect to $\mathrm{HCV}$, it has been reported that approximately $3 \%$ of the world population are

187 infected with HCV. About $75 \%$ of patients acutely infected with HCV developed a chronic liver 188 disease, of which, 3-11\% developed liver cirrhosis, which may eventually lead to hepatocellular 189 carcinoma (HCC) (Alter 2006; Micallef et al. 2006; Poynard et al. 2003; Somi et al. 2014). In the 190 development of VLP-based vaccines against HCV infection, HBsAg-derived VLPs have been 191 used to display the heterologous antigenic epitope hypervariable region 1 (HVR1) of HCV 192 (Vietheer et al. 2007). Following the vaccination of mice with chimeric HBV VLPs expressing 193 HVR1, humoral immune response was manifested as the production of HVR1 specific antisera in 194 immunized animals. Moreover, in vitro studies also demonstrated the protective effects of the 195 vaccine (Vietheer et al. 2007). Surprisingly, the antigenicity and immunogenicity of HBsAg were preserved even after the insertion of the HVR1 peptide. This finding potentially paves way 197 to the development of multivalent hepatitis vaccines.

HCV VLPs are commonly synthesized by expressing viral glycoproteins E1 and E2. The 199 efficacy of HCV VLP vaccine was extensively tested in different animal models, including mouse and baboon, and yielded satisfactory results (Jeong et al. 2004; Lechmann et al. 2001; 
201 Murata et al. 2003; Qiao et al. 2003). Recently, chimpanzees, the only HCV-susceptible animal 202 model, were used to evaluate the protective efficacy of HCV VLPs. These immunization studies 203 suggested that HCV VLPs were capable of conferring protection upon the vaccinated animals 204 against HCV challenge by eliciting E1- and E2-specific humoral and cell-mediated immune 205 responses (Elmowalid et al. 2007). Similarly, in a different study, enveloped retroviral VLPs 206 pseudotyped with heterologous HCV E1 and E2 glycoproteins also elicited strong cross207 reactivity in both mouse and macaque (Garrone et al. 2011). It was reported that E1- and E2208 specific neutralizing antibody responses might be the major effectors against HCV infection 209 (Beaumont \& Roingeard 2013; Pestka et al. 2007).

210 Non-virus induced HCC cannot be treated with preventive vaccine, but a VLP-based antitumor 211 vaccine has been previously described by Zhang et al. (2007), who successfully incorporated 212 tumor associated antigens (TAAs) of $\mathrm{HCC}$, which include melanoma associated antigen 1 213 (MAGE-1), melanoma associated antigen 3 (MAGE-3), and $\alpha$-fetoprotein (AFP1), into HBV 214 core antigen $(\mathrm{HBc})$ derived VLPs. Similarly, to the native viruses, these chimeric HBc VLPs 215 could be presented by DCs. Immunization with DCs pulsed with chimeric HBc VLPs also activated strong CTL immune responses that correlated with decreased mortality of immunized animals. Pulsing DCs with VLPs was expected to improve the danger signal and DC presentation, and thereby enhance immunization efficiency (Zhang et al. 2007).

219 Recently, chimeric HBc VLPs bearing the HBV x protein (HBx) were produced by Ding et al. 220 (2009). The HBx gene is commonly integrated into hepatocyte DNA and plays a pivotal role in tumorigenesis of HBV-associated HCC (Arbuthnot et al. 2000; Schaefer et al. 1998; Ye et al. 2008). HBV infected hepatocytes and associated HCC were demonstrated to express this viral antigen ( $\mathrm{Su}$ et al. 1998). Vaccination of mice with HBc VLPs expressing HBx either in the form 
224 of active immunization or by an adoptive transfer has resulted in specific cell-mediated immune

225 responses (Ding et al. 2009). Most of the VLP-based vaccines designed against HBV-associated

226 HCC are preventive and aimed to eliminate HBV viruses by targeting a specific viral antigen but

227 intriguingly, this therapeutic vaccine was designed to target the viral antigen expressed by

228 infected hepatocytes.

\section{3.2 Human papilloma virus-associated cervical cancer}

$230 \mathrm{HPV}$ is the main causative agent of cervical cancer (CC). According to the American Cancer

231 Society, the survival rate of CC patients varies between $15 \%$ and $93 \%$, depending on cancer

232 stage. It was reported that nearly $100 \%$ of women with CC were found to be HPV positive, of

233 which, HPV-16 and HPV-18 accounted for approximately 70\% of all CC cases (Nour 2009). To

234 date, the most effective way of $\mathrm{CC}$ prevention is early vaccination against HPV. Multivalent

235 Gardasil, Cervarix, and Gardasil 9, which mainly target HPV-16 and HPV-18, are the only

236 licensed preventive VLP-based HPV vaccines available on the market. These commercially

237 available HPV vaccines were developed based on HPV VLPs that express L1, the major capsid

238 protein of HPV (Kushnir et al. 2012). Despite the success of HPV vaccination programs, these

239 preparations are type-restricted and, therefore, do not target less prevalent but high-risk HPV

240 subtypes that cause about $30 \%$ of CC cases (Tjalma et al. 2013). Furthermore, the high cost of

241 vaccine production has also prompted scientists to develop a broader spectrum second generation

242 HPV vaccine. It is generally believed that the highly conserved L2 minor capsid protein of HPV

243 is an ideal candidate for second generation HPV vaccines (Tyler et al. 2014). L2 is one of the

244 structural proteins produced during the later stage of HPV replication (Graham 2010).

245 Vaccination with L2 peptide elicited cross-neutralizing antibodies and conferred cross-protection

246 upon immunized animals, although the induced antibody titer was significantly lower than that 
247 stimulated by HPV L1-based VLP (Gambhira et al. 2007; Pastrana et al. 2005). Therefore, Pineo

248 et al. (2013) created a new vaccine by incorporating L2 into the C-terminal region of L1 in an

249 attempt to improve its immunogenicity. The fusion peptide L1/L2 was expressed in Nicotiana

250 benthamiana and L2 was found to be exposed on the surface of L1/L2 chimeric VLPs.

251 Immunization studies demonstrated that L1/L2 chimeric VLPs induced both L1- and L2-specific

252 humoral immune responses and conferred cross-protection upon immunized mice against HPV-

25316 and HPV-52 (Pineo et al. 2013). Similar studies were carried out by Huber et al. (2015), in

254 which a cross-neutralizing epitope of the L2 protein of HPV-45 was incorporated into HPV-18

255 L1 protein. The resulting chimeric VLP vaccine 18L1-45RG1 was observed to cross-protect

256 against HPV-18, HPV-39, HPV-45, and HPV-68 when mice were passively immunized with

257 antisera from the 18L1-45RG1 immunized rabbits (Huber et al. 2015). Remarkably, a much

258 boarder spectrum L2-expressing HPV VLP vaccine was recently reported to be capable of cross-

259 neutralizing $24 \mathrm{HPV}$ subtypes in vitro, while conferring cross-protection upon the immunized

260 animals against 21 HPV subtypes (Schellenbacher et al. 2013).

261 To date, all commercially available CC vaccines are prophylactic HPV vaccines. The lack of a

262 therapeutic vaccine makes it impossible to cure pre-existing HPV-associated CC. Nevertheless,

263 an attempt to develop a therapeutic vaccine against HPV was undertaken by inserting the non-

264 structural E7 protein of HPV into infectious bursal disease virus VLPs (VLP E7) (Martin

265 Caballero et al. 2012). The E7 protein is a tumor-specific antigen (TSA), which is highly

266 expressed in HPV-associated CC. It is suggested to be an important element in the maintenance

267 of transformed phenotype of cancerous cells (Baker et al. 1987; DeFilippis et al. 2003; Psyrri et

268 al. 2004). Tumor challenge followed by vaccination of mice with VLP E7 demonstrated a 269 complete rejection of the tumor (Martin Caballero et al. 2012). 
270 To improve CTL activity, an MHC class II restricted T-cell epitope was inserted into VLPs. In

271 particular, Jemon et al. (2013) incorporated the pan HLA DR-binding epitope (PADRE), a potent

272 T-cell inducer, into rabbit hemorrhagic disease virus VLPs expressing the E6 protein (RHDV

273 VLP). Similar to E7, E6 is a TSA expressed in HPV-associated CC that plays a major role in

274 malignant conversion (Yim \& Park 2005). The combination of E6-RHDV-VLP-PADRE vaccine

275 with antibody treatments reactivated T cells, reduced TC-1 tumor outgrowth, and increased the

276 survival rate of immunized animals (Jemon et al. 2013). Apart from CC, HPV was also reported

277 to cause cancers of the vulva, vagina, penis, anus, as well as oropharynx cancers (Ljubojevic \&

278 Skerlev 2014). Therefore, HPV vaccines have potential to confer a certain degree of protection

279 against these HPV-associated diseases.

3.3 Pancreatic cancer

281

282

283

284

285

286

287

288

289

290

291

292

Pancreatic cancer is a highly aggressive cancer, which is currently ranked as one of the top five causes of cancer-related mortality (Gostimir et al. 2016). The average survival rate of pancreatic cancer patients from the onset of diagnosis is approximately $20 \%$ and decreases dramatically to $6 \%$ within 5 years (Sannino et al. 2016). The extremely low 5-year relative survival rate of pancreatic cancer patients is largely attributed to the lack of disease-specific symptoms and early cancer cell dissemination (Oberstein \& Olive 2013; Rhim et al. 2012). Current treatments of pancreatic cancer rely heavily on conventional therapies, such as surgery, chemotherapy, and radiotherapy.

Trop2 is one of the tumor-associated antigens (TAAs), which is overexpressed in many epithelial carcinomas. Overexpression of this protein is often associated with tumorigenesis, metastasis, decreased overall survival rate, and tumor grade (Cubas et al. 2009; Fong et al. 2008). Limited expression of Trop2 by healthy cells makes it a promising TAA for cancer immunotherapy 
293 targeting (Cubas et al. 2009). Recently, Trop2 was incorporated into enveloped simian

294 immunodeficiency virus VLPs in order to generate chimeric mTrop2 VLPs (Cubas et al. 2011).

295 Immunization of mice with mTrop2 VLPs alone following a tumor challenge significantly

296 reduced tumor size and increased mouse life expectancy by approximately 36\% (Cubas et al.

297 2011). The higher survival rate (70\%) was achieved when mice immunized with mTrop2 VLPs

298 were also treated with gemcitabine (Cubas et al. 2011). Immunization with mTrop2 VLPs

299 overcame self-tolerance and elicited both innate and cell-mediated immunities manifested by the

300 elevation of levels of antigen-specific tumor-infiltrating T lymphocytes, natural killer (NK) cells,

301 and NK T-cells. In contrast, the numbers of immunosuppressive MDSCs and Tregs as well as the

302 levels of immunosuppressive cytokines were notably reduced by this immunization. Furthermore,

303 expression levels of IL-2, IL-13, and IFN- $\gamma$ were enhanced by mTrop2 VLP administration,

304 demonstrating Th1-skewed immune responses that are necessary for the destruction of cancer

305 cells. In addition, mTrop2-specific antibodies were detected in the serum and demonstrated to

306 play a critical role in mediating cell cytotoxicity against cancerous cells (Cubas et al. 2011).

307 Intriguingly, a recombinant simian/human immunodeficiency virus (SHIV) also has been 308 recruited as backbone for the production of VLP-based pancreatic cancer vaccine. The first 309 SHIV VLPs were produced by a baculovirus expression system using the protein transfer 310 technique (Yao et al. 2000). Following the development of SHIV VLPs, Li et al. (2008)

311 incorporated the recently identified pancreatic cancer TAA mesothelin (MSLN) into SHIV VLPs.

312 MSLN is commonly overexpressed in pancreatic cancer cells, and it has been shown to cause 313 metastasis in ovarian cancer cells when it interacts with mucin 16 (Gubbels et al. 2006). Due to 314 its low expression level in healthy cells, MSLN was recently listed as a potential biomarker for 315 early detection of pancreatic cancer (Laheru \& Jaffee 2005). Previous studies showed that mice 
316 immunized with chimeric SHIV VLPs expressing human MSLN (hMSLN VLP) were protected

317 from tumor challenge and their life expectancy increased to $\sim 60 \%$ (Li et al. 2008).

318 Immunization with hMSLN VLPs of mice grafted with human pancreatic cancer cells elicited

319 both cellular and humoral immunities, in particular, strong CTL activity, which resulted in a

320 significant reduction of tumor mass. High population of IFN- $\gamma$-secreting $\mathrm{T}$ lymphocytes also

321 indicated Th1-skewed immune responses. The numbers of immunosuppressive lymphocytes,

322 including different subsets of Tregs, decreased significantly upon immunization, which

323 correlated with prolonged survival of immunized mice (Li et al. 2008). As hMSLN and mouse

324 MSLN (mMSLN) only share about 55\% homology in amino acid sequence, strong immune

325 responses elicited in a previous study ( $\mathrm{Li}$ et al. 2008) could be attributed to xenogeneic immune

326 responses against hMSLN (Wang et al. 2009). To investigate the capability of the vaccine to

327 break self-tolerance, Zhang et al. (2013) continued the study by substituting hMSLN with

328 mMSLN to generate chimeric, mMSLN-expressing VLPs (mMSLN VLPs). Surprisingly,

329 immunization with mMSLN VLPs followed by a tumor challenge in mice has successfully

330 broken self-tolerance and elicited strong mMSLN-specific CTL activity that significantly

331 reduced tumor mass and increased the overall survival rate of the animals. Notable reduction in

332 the frequency of Tregs was also believed to be one of the major drivers of cancer growth

333 inhibition (Zhang et al. 2013).

334 In addition to its association with pancreatic cancer, MSLN is also commonly expressed in

335 mesothelioma, ovarian cancer, lung cancer, acute myeloid leukemia, and uterine serous

336 carcinoma (Chang \& Pastan 1996; Frierson et al. 2003; Ho et al. 2007; Steinbach et al. 2007). As

337 a common TAA in different cancer cells, the capability of MSLN-expressing VLPs to confer

338 cross-protection against different tumor challenges is an interesting area to explore. 


\subsection{Prostate cancer}

340 Prostate cancer is one of the leading causes of cancer-related mortality among men in the United

341 States and Western Europe and is ranked as the third most common cancer in Europe (Ferlay et

342 al. 2013). Early stage localized prostate cancer is often treated with prostatectomy, hormonal

343 therapy, and radiotherapy (Wilt \& Ahmed 2013). However, almost all patients with advanced

344 prostate cancer tend to experience bone metastasis that reduces the effectiveness of early

345 therapies (Msaouel et al. 2008). Chymotrypsin-like serine proteases or prostate specific antigens

346 (PSAs) are prostatic secretory proteins that commonly serve as biomarkers for the detection of

347 prostate cancer because they are highly expressed by prostate cancer cells (Koie et al. 2015).

348 These androgen-regulated antigens are expressed in extremely low levels in non-prostate healthy

349 tissues and in normal prostate tissues. Therefore, they are appropriate tumor antigens for cancer

350 targeting as prostate tumors overexpress PSA (Cunha et al. 2006). To date, the only licensed

351 therapeutic prostate cancer vaccine available on the market is Sipuleucel-T, a cell-based

352 preparation that involves leukapheresis and in vitro DC activation (Graff \& Chamberlain 2015).

353 In VLP-based prostate cancer vaccine development, chimeric murine polyomavirus VLPs that

354 harboring full length PSA (PSA-MPy VLPs) conferred partial protection from prostate tumor

355 challenge in mice and the maximum protection was achieved only when PSA-MPy VLPs were

356 loaded onto DCs in the presence of $\mathrm{CpG}$ as an adjuvant (Eriksson et al. 2011). Both CTL activity

357 and $\mathrm{CD}^{+}$immune responses were observed following the immunization but not the humoral

358 immune responses, because PSA antigen was speculated to be buried inside the viral capsid, and

359 therefore, remained inaccessible by B cells (Eriksson et al. 2011). Loading the VLPs into DCs is

360 expected to activate the latter and enhance the danger signal. Nevertheless, immunotherapy using 
361 PSA as a tumor antigen will most likely result in prostate destruction due to autoimmune

362 reactions directed against PSA, which is also expressed on normal prostate tissues.

\section{$363 \quad 3.5$ Breast cancer}

364 Breast cancer is a notorious fatal illness that primarily affects women. Its 5-year relative survival 365 rate is the highest at the early stage (nearly $100 \%$ ) and drops to $22 \%$ at stage IV or metastatic 366 stage (Torre et al. 2015). The most common treatment of breast cancer includes invasive 367 mastectomy that may severely impact body self-esteem (Markopoulos et al. 2009). A VLP-based 368 breast cancer vaccine has been developed by incorporating the breast cancer TAA HER-2/neu 369 (Her2) into murine polyomavirus VLPs to generate chimeric Her2 ${ }_{1-683}$ Py VLPs (Tegerstedt et al. 2005). Her2 has been commonly used as a biomarker for early detection of breast cancer, and its overexpression is often associated with tumor growth, increased mortality, and cancer relapse rate (Ross et al. 2003). In vivo immunization studies followed by tumor challenge indicated that a single vaccination with Her2 ${ }_{1-683}$ Py VLPs was sufficient to elicit a strong Her2-specific cellular immunity that led to tumor rejection and longer survival period. Immunization with $\mathrm{Her} 2{ }_{1-683} \mathrm{Py}$ VLPs of transgenic mice expressing mutated Her2 oncogene also resulted in complete protection against tumor outgrowth, demonstrating preventive efficacy of the vaccine (Tegerstedt et al. 2005). However, immunization timing seems to have major consequences on vaccine efficacy as delayed immunization only postponed tumor outgrowth without conferring any significant protection (Tegerstedt et al. 2005). Humoral immunity was not detected in that study as Her2 was probably expressed internally within the VLPs. As previously mentioned, loading VLPs into DCs may enhance DC activation. In a more recent study by the same group, Tegerstedt et al. (2007) loaded Her $2_{1-683}$ Py VLPs into murine DCs and immunized mice with such activated DCs. 
384 of Her $2_{1-683}$ Py VLPs was required to confer protection against tumor challenge if VLPs were 385 loaded into DCs (Tegerstedt et al. 2007). Polyomavirus VLP-based vaccine preparations have an 386 advantage over other VLPs due to the fact that numerous polyomavirus receptors are expressed 387 on different cells, including sentinel cells (Drake et al. 2000).

388 Furthermore, enveloped VLPs also have been used to display Her2. Patel et al. (2015b) modified 389 Her2 TAA to a glycosylphosphatidylinositol (GPI)-anchored form and incorporated the fusion 390 GPI-HER2 protein into enveloped influenza VLPs. The newly created vaccine (GPI-HER2-VLP) 391 was shown to be immunogenic and capable of activating both cellular and humoral immune 392 responses. The survival rate of mice immunized with GPI-HER2-VLP increased to 393 approximately 66\%. Intriguingly, Her2-specific antibody level was found to be similar in mice 394 immunized with GPI-HER2-VLP and GPI-HER2. However, the latter treatment failed to confer significant protection against tumor challenge, indicating that the cellular immunity must play a major role. This correlated well with Th1-skewed immune response observed in the study (Patel et al. 2015b). Her2 is a novel TAA, which is also overexpressed in many different cancers, such as endometrial carcinoma, gastric cancer, salivary duct carcinoma, lungs adenocarcinoma, and ovary cancer (Chiosea et al. 2015; Meza-Junco et al. 2011; Ruschoff et al. 2012; Santin et al. 2008). However, apart from the case of breast cancer, the potential of Her2-bearing VLPs as vaccine candidates against other types of cancer has yet to be investigated.

\subsection{Skin cancer}

Skin cancer is generally divided into melanomas and non-melanomas, and it has been reported to

404 be one of the most common cancers in the world (Simoes et al. 2015). White population is 405 usually more susceptible to skin cancer than other races (Narayanan et al. 2010). To date, there is no available vaccine against skin cancers, but a bacteriophage Q $\beta$ VLP-based melanoma cancer 
407 vaccine (MelQbG10) developed by Cytos Biotechnology AG has now completed its Phase 2

408 clinical trial and is expected to be the first melanoma cancer vaccine on the market (Goldinger et

409 al. 2012; Kushnir et al. 2012). Other VLPs, including those based on extensively studied HBc

410 capsid, were recently utilized in VLP-based melanoma vaccine development as demonstrated by

411 Kazaks et al. (2008). In this vaccine, melanoma associated antigen 3, a TAA whose

412 overexpression is often associated with poor prognosis and melanoma metastasis, was

413 incorporated into HBc VLPs. To further improve the immunogenicity of the vaccine, single-

414 stranded $\mathrm{CpG}$ oligonucleotides were packaged into the VLPs. Although the immunogenicity of

415 this vaccine has yet to be investigated in vivo, it is expected that it will be a suitable vaccine

416 candidate to elicit strong cellular immunity (Kazaks et al. 2008).

417 In another report, Brinkman et al. (2005) incorporated H-2K $\mathrm{K}^{\mathrm{b}}$-restricted ovalbumin (OVA) $257-264$

418 epitope and $\mathrm{H}-2 \mathrm{~K}^{\mathrm{b}}$-restricted CTL epitope of melanoma differentiation antigen tyrosinase-related

419 protein 2 (TRP2) into $\mathrm{VP}_{1}$ of murine polyomavirus VLPs (PLP), generating chimeric PLP (VP $1^{-}$

$\left.420 \mathrm{OVA}_{252-270} \mathrm{PLP}\right)$ and chimeric murine polyomavirus like pentamers $\left(\mathrm{VP}_{1}-\mathrm{TRP} 2_{180-192} \mathrm{PP}\right)$,

421 respectively. In vivo studies of $\mathrm{VP}_{1}-\mathrm{OVA}_{252-270} \mathrm{PLP}$ in mice showed that notable protection

422 against OVA-expressing melanoma cells was conferred by the induction of strong CTL activity.

423 Although $\mathrm{VP}_{1}-\mathrm{TRP} 2_{180-192}$ PP failed to assemble into VLPs, surprisingly it partially protected

424 immunized animals from lethal melanoma challenge (Brinkman et al. 2005). These PLP-based

425 vaccines demonstrated highly efficient antigen carriers for inducing CTL responses, underlining

426 their potential as immunotherapeutic against cancer.

427 In addition, rabbit hemorrhagic disease virus (RHDV) VLPs have been recruited as tumor

428 antigen delivery system because this virus does not infect humans (Steinmetz et al. 2010).

429 RHDV VLPs have an advantage over human-infecting viruses, such as HBV or polyomavirus, as 
430 pre-existing immunities of the vaccinated individual may interfere with successful treatments.

431 RHDV VLPs were engineered to express the model antigen gp33 and conjugated with $\alpha$ -

432 galactosylceramide that acted as an immunostimulatory adjuvant. Vaccination of mice followed

433 by tumor challenge with B16 melanoma expressing gp33 activated intense CTL and invariant

434 NKT activity manifested by significant elevations of IL-4 and IFN- $\gamma$ levels (McKee et al. 2012;

435 Tomura et al. 1999).

3.7 Other cancers

\subsubsection{Lung cancers}

439

440

441

442

443

444

445

446

447

448

449

450

451

A VLP-based vaccine against lungs metastases has been established by incorporating the TAA isoform 2 of the tight junction molecule claudin-18 (CLDN18.2) into HBc VLPs (Klamp et al. 2011). Immunization of mice with this vaccine followed by a tumor challenge with CLDN18.2expressing CT26 colon cancer cells resulted in lower tumor burden around the lung areas (Klamp et al. 2011). Protection conferred by this VLP-based vaccine was largely mediated by complement-dependent cytotoxicity and antibody-dependent mediated cytotoxicity. Surprisingly, antibodies elicited by this vaccine were highly specific against CLDN18.2 and not cross-reactive with CLDN18.1 variant, which is normally expressed on healthy lung tissue, despite high homology of their protein sequences (Klamp et al. 2011).

\subsubsection{Epstein-Barr virus related cancers}

Burkitt's lymphoma, Hodgkin lymphoma, B cell lymphoma, nasopharyngeal carcinoma, gastric and sporadic carcinoma may develop in Epstein-Barr virus (EBV) infected individuals (Hjalgrim et al. 2007; Thompson \& Kurzrock 2004). In fact, EBV infects more than $90 \%$ of the worldwide 
452 population, but most people remain asymptomatic. However, cancer development may be

453 triggered in EBV-infected individuals by numerous factors (Hjalgrim et al. 2007). Recently,

454 chimeric Newcastle disease virus (NDV) VLPs containing heterologous antigenic glycoprotein 455 gp350/220 of EBV (EBVgp350/220-F VLP) were established and vaccination of mice with 456 EBVgp350/220-F VLPs elicited long-lasting gp350/220-specific antibodies capable of 457 neutralizing EBV in vitro (Ogembo et al. 2015). In addition, antibodies detected in the sera of 458 immunized animals were predominantly of IgG1 subclass, indicating a Th2-skewed immune 459 response (Ogembo et al. 2015). EBV VLPs were also previously reported as a potential 460 prophylactic vaccine candidate against EBV. Immunization of EBV VLPs in mice elicited not 461 only humoral immune response but also cellular mediated immune response. (Ruiss et al. 2011).

462 CTL immune response characterized by activation of EBV-specific CD8+ T cells induced by 463 EBV VLP is speculated to be attributed to the EBV mRNA encapsidated within the VLP which 464 is then translated in the infected cells and presented via the MHC class I molecules (Jochum et al. 465 2012). However, no viral DNA was detected in the EBV VLPs indicating the particles are non466 infectious and non-replicative VLPs (Ruiss et al. 2011).

4.0 Extracellular Vesicles Versus VLPs in Cancer Vaccine development.

Extracellular vesicles (EVs) refer to microvesicles and exosomes released by cells into their extracellular space (Gould \& Raposo 2013). For decades, EVs have been recognized as cellular garbage with no significant biological function but recently, they have been identified as an

472 important carriers in intercellular signaling, drug delivery and vaccine development (Nolte-'t

473 Hoen et al. 2016; Tominaga et al. 2015). Morphologically, EVs resemble viral particles but 474 cannot replicate as viruses and often encapsulate fragments of proteins, peptides and nucleic 
475 acids (Kourembanas 2015; Wurdinger et al. 2012). Intriguingly, EVs released from virus

476 infected and tumor cells may also contain viral and tumor antigens, respectively (Al-Nedawi et al.

477 2008; Nolte-'t Hoen et al. 2016). For example, tumor cell-derived exosomes were demonstrated

478 to contain a tumor antigen which could effectively prime the CTL immune responses, but the

479 EVs were shown to induce cancerous phenotypic changes in healthy cells, posing a serious risk

480 of tumorigenesis (Melo et al. 2014; Wolfers et al. 2001). APC derived EVs are likely to be more

481 effective and safer candidates to be recruited in cancer vaccine development as they naturally

482 present MHCs, co-stimulatory and adhesion molecules on their surface, readily facilitating the 483 activation of B and T cell immunities (Nolte-'t Hoen et al. 2009; Raposo et al. 1996). Conversely,

484 VLPs lack these surface molecules and activation of $\mathrm{B}$ and $\mathrm{T}$ cell immunities can be achieved via 485 recognition of PAMP of VLPs (Yan et al. 2015). Attributed to the viral origin of the VLPs, they 486 are mostly immunogenic even in the absence of an adjuvant whereas most EVs are poorly 487 immunogenic (Zhu et al. 2017). Although EVs can also be modified genetically to carry or 488 display specific antigens, surface modification of EVs is mostly achieved by using the protein 489 transfer technology or the surface display technology in which a foreign protein or a peptide is 490 fused with the transmembrane proteins of the EVs via genetic engineering followed by 491 expression in a suitable protein expression system (Stickney et al. 2016).

\subsection{Potential drawbacks of VLPs in cancer vaccine development}

Despite promising results presented by VLPs, there are two major drawbacks of using VLPs as a 495 platform in cancer vaccine development. One of the major concerns is the pre-existing immunity 496 of an immunized individual against the VLPs which function as nanocarriers for epitopes or 497 therapeutic peptides. This phenomenon is known as carrier induced epitopic suppression (CIES), 
498 characterized by suppression of antibody responses directed against the antigen conjugated to an

499 immunogenic carrier due to the pre-existing immunity against the carrier (Herzenberg \&

500 Tokuhisa 1982). However, the effect of CIES can be mitigated and the peptide specific immune

501 response can be enhanced by increasing the copy number of peptides displayed on the surface of

502 the VLPs, repeated injections or higher doses of peptide conjugated VLP vaccines (Jegerlehner

503 et al. 2010; Kjerrulf et al. 1997). Alternatively, CIES can be avoided by careful selection of a

504 VLP-based carrier. For instance, VLPs of non-human origin should be selected in the

505 development of vaccines for human use (McKee et al. 2012).

506 Another impediment in VLP-based vaccine development is the cost of production. A vaccine

507 candidate is unlikely to be competitive in the market if its manufacturing process is not scalable

508 due to cost ineffectiveness even if it yields a promising pre-clinical outcome. For instance,

509 current HPV VLP-based vaccine costs approximately US\$360 for the full regimen in the United

510 State, a price which is not widely affordable in many developing countries where the CC is

511 actually most prevalence (Madrid-Marina et al. 2009; Wang \& Roden 2013). Production cost of

512 VLP-based vaccine is heavily reliance on the design of the VLPs and the expression systems

513 used. Bacterial expression systems are widely adopted for VLPs production due to its

514 inexpensive set up, but the system lacks post-translational modification machinery, which often

515 leads to the formation of misfolded protein, reduced protein solubility, low yield or cell death

516 (Terpe 2006). Therefore, majority of the commercialized vaccines are expressed in eukaryotic

517 cells (yeast, insect or mammalian cells) equipped with post-translational modification machinery.

518 Nonetheless, these expression systems often required greater operational costs and this

519 eventually increases the cost of the end products (Khan 2013; Kushnir et al. 2012). 
521

522 Cancers that emerge following infectious diseases are notorious killers worldwide. Vaccination

523 against such cancers is speculated to be the most effective approach in cancer prevention and 524 treatment. VLPs are promising candidates in cancer vaccine development due to their 525 characteristics such as stability and capability of self-assembly. These prerequisite features are 526 required for packaging and delivery of bioactive materials, such as tumor antigens, antibody 527 fragments, immunodominant regions, short peptides, DNA, or RNA. Construction of chimeric 528 VLPs depends on the nature of the VLPs. Although both non-enveloped and enveloped VLPs 529 can be produced by genetic manipulation, the surface chemical modification and protein transfer technology represent alternatives for the production of non-enveloped and enveloped VLPs, respectively with minimum genetic modifications. In addition, VLPs containing PAMP can be used in the development of self-adjuvating vaccines, mitigating the reliance on the use of adjuvants which is often associated with some undesired side effects.

In treating or preventing HBV-related diseases, VLPs carrying fragments of antibodies against HBsAg and the ' $a$ ' determinant of HBV were invented as new therapeutic and preventive vaccine candidates, respectively (Pleckaityte et al. 2015; Tan \& Ho 2014; Yong et al. 2015a). Furthermore, VLPs carrying HCV glycoproteins E1 and E2 can be potentially developed into HCV preventive vaccines. These chimeric VLPs have been demonstrated to induce specific humoral immune response in immunized mice. With respect to HPV related diseases, approximately $70 \%$ of cervical cancer cases caused by the most virulent strains HPV-16 and 18 can be prevented by current prophylactic vaccines on the market (Nour 2009). To combat the remaining $30 \%$ of cervical cancer cases caused by less prevalent but, nonetheless, high-risk virulent strains, preparations that utilize highly conserved L2 minor capsid protein of HPV are 
544 currently being tested. In particular, a new fusion vaccine has been created by incorporating L2

545 minor capsid protein of HPV into VLPs. Schellenbacher et al. (2013) showed that such

546 multivalent HPV vaccines (L1/L2 chimera) could cross-neutralize more than 20 HPV subtypes

547 both in vitro and in vivo, paving way to the development of low cost, broad spectrum HPV

548 prophylactic vaccines. On the other hand, the VLP-based therapeutic CC vaccines were

549 developed to target E7 and E6 proteins expressed by the HPV-associated CC. These VLP-based

550 vaccines could represent a curative treatment to patients with pre-existing HPV-associated CC

551 and they can also be engineered to induce a desired immune response by fusing with specific

552 immunostimulatory molecules via genetic engineering approaches. For instance, MHC class II

553 restricted $\mathrm{T}$ cells epitope was incorporated into the RHDV VLPs to favor the proliferation and

554 activation of T cells which in turn enhance CTL immune responses (Jemon et al. 2013).

555 Besides oncovirus-related cancers, other forms of cancer without a known etiology agent can

556 also potentially be treated with VLP-based therapeutic vaccines by inserting tumor antigens into

557 the viral envelop or capsid proteins followed by antigen presentation on the target tumor side.

558 Highly aggressive pancreatic cancer may be potentially treated with Trop2 TAA incorporated

559 into the envelope of SIV VLPs, although co-administration with gemcitabine may be required for

560 optimal protection (Cubas et al. 2011). Similarly, the insertion of mesothelin into SHIV VLPs

561 also induced significant anti-tumor responses. Furthermore, prostate cancer may be potentially

562 prevented with immunotherapy that comprises PSA incorporated MPy VLPs. Co-administration

563 of VLP-based vaccine loaded into DCs with $\mathrm{CpG}$ oligonucleotides as adjuvant could protect

564 against tumor outgrowth. In preparations of putative vaccines against breast cancer, the TAA

565 Her2 was incorporated into murine polyomavirus VLPs (Tegerstedt et al. 2005) and enveloped

566 influenza VLPs (Patel et al. 2015b). Both approaches led to the induction of cellular and humoral 
567 immune responses; moreover, loading VLPs into DCs was demonstrated to synergistically

568 improve immunization efficiency in a murine polyomavirus model. VLPs utilized in therapeutic

569 skin cancer vaccine preparations include bacteriophage $\mathrm{Q} \beta, \mathrm{HBc}$ capsid, murine polyomavirus, 570 and RHDV. Potential VLP-based therapeutic and preventive cancer vaccines have also been

571 proposed for lung and EBV related cancers.

572 Morphologically, EVs resemble viral particles, and the former are important carriers in 573 intercellular signaling, vaccines and drug delivery systems. Similar to VLPs, EVs were 574 employed as a platform for cancer vaccine development owing to their unique features in 575 harboring and displaying tumor antigens. Nevertheless, the challenges faced by EV-based 576 carriers include safety, immunogenicity and efficacy, which must be addressed properly in the

577 future. In fact, due to the natural occurrence of EVs in the cells, most of the studies about EV-

578 based carriers in the past were mainly focused on drug delivery system instead of vaccine 579 development (Ohno et al. 2016; Tominaga et al. 2015). However, EVs derived from the surface 580 of APC containing MHCs, co-stimulatory and adhesion molecules have potential in vaccine 581 development.

582 Pre-existing immunity of the immunized individuals and cost of vaccine production are the two 583 major drawbacks of using VLPs as a platform in vaccine development. Pre-existing immunity 584 against VLPs could interfere the efficacy of any subsequent vaccination involving the same VLP 585 via CIES. Although the effect of CIES can be alleviated by several approaches, a careful 586 selection of VLPs could avoid CIES. On the other hand, vaccine production must be cost 587 effective and scalable. Ideally, to eradicate a preventable disease, a vaccine must be affordable 588 for everyone in the globe, especially the developing countries where the diseases are actually 589 most prevalence. 
590 In conclusion, efficacy of the VLP-based vaccine is highly dependent on the selection of tumor 591 antigens and the design of VLPs. In order to produce an effective VLP-based vaccine, the 592 genetic factor of an individual tumor has to be taken into consideration during the selection of 593 the tumor antigen because mutations of the tumor cells vary considerably from person to person 594 even they are diagnosed with the same kind of cancer (Castiblanco \& Anaya 2015; Ott et al. 595 2017). In the process of selecting and designing VLPs, the effect of CIES due to pre-existing 596 immunity must be mitigated or possibly avoided. VLPs have to be designed in a way that they 597 could effectively activate the innate and adaptive immunities and this could be achieved by 598 selecting highly immunogenic VLPs, conjugation or co-administration of VLPs with adjuvants 599 or other immunostimulatory molecules. All of all, VLPs have great potential in cancer vaccine 600 development. 
602

603

604

605

606

607

608

609

610

611

612

613

614

615

616

617

618

619

620

621

622

623

\section{Figure legend}

Figure 1. A schematic diagram of virus-like particles (VLPs) production using different approaches. a) Production of non-enveloped chimeric VLPs using genetic alteration. Viral structural protein is fused with a foreign antigen via genetic engineering followed by the expression of the chimeric protein in a suitable host system. b) Production of non-enveloped chimeric VLPs by chemical conjugation. Non-enveloped VLPs are produced by expressing a viral structural protein, and surface decoration of the VLPs is achieved by conjugating a foreign antigen to the VLPs, and c) production of enveloped chimeric VLPs by the protein transfer approach. Enveloped VLPs are produced by expressing the viral proteins in suitable host cells followed by incubating with the glycosylphosphatidylinositol (GPI)-anchored proteins. The foreign antigens are then transferred to the lipid bilayer of the VLPs.

Figure 2. A schematic diagram of virus-like particle (VLP) in triggering specific immune responses against tumor cells. Chimeric VLPs displaying tumor antigen (red oval) on their surface are administered into an animal model. Tumor antigen is taken up, processed, and presented by dendritic cells (DCs) to respective T cells. Presentation of tumor antigen by DCs converts naïve cytotoxic and helper $T$ cells into cytotoxic $\left(\mathrm{T}_{\mathrm{c}}\right)$ and effector helper $(\mathrm{Th}) \mathrm{T}$ cells, respectively. $T_{c}$ cells (red triangles) kill tumor cells by releasing cytotoxic proteins, such as granzyme and perforin. $\mathrm{Th}_{1}$ cells support the activation of $\mathrm{T}_{\mathrm{c}}$ cells by releasing interleukin-2 (IL2) and interferon gamma (IFN $\gamma$ ), whereas $\mathrm{Th}_{2}$ cells stimulate B cells to produce tumor antigenspecific antibodies, which are capable to bind and mark (red triangles) tumor cells for effective killing by natural killer (NK) cells and phagocytes. 
627

628

629

630

631

632

633

634

635

636

637

638

639

640

641

642

643

644

645

646

647

648

649

650

651

652

653

654

655

656

Al-Nedawi K, Meehan B, Micallef J, Lhotak V, May L, Guha A, and Rak J. 2008. Intercellular transfer of the oncogenic receptor EGFRvIII by microvesicles derived from tumour cells. Nat Cell Biol 10:619-624. 10.1038/ncb1725

Altekruse SF, Henley SJ, Cucinelli JE, and McGlynn KA. 2014. Changing hepatocellular carcinoma incidence and liver cancer mortality rates in the United States. $\mathrm{Am} \mathrm{J}$ Gastroenterol 109:542-553. 10.1038/ajg.2014.11

Alter MJ. 2006. Epidemiology of viral hepatitis and HIV co-infection. J Hepatol 44:S6-9. 10.1016/j.jhep.2005.11.004

Arbuthnot P, Capovilla A, and Kew M. 2000. Putative role of hepatitis B virus X protein in hepatocarcinogenesis: effects on apoptosis, DNA repair, mitogen-activated protein kinase and JAK/STAT pathways. J Gastroenterol Hepatol 15:357-368.

Baker CC, Phelps WC, Lindgren V, Braun MJ, Gonda MA, and Howley PM. 1987. Structural and transcriptional analysis of human papillomavirus type 16 sequences in cervical carcinoma cell lines. J Virol 61:962-971.

Barth H, Ulsenheimer A, Pape GR, Diepolder HM, Hoffmann M, Neumann-Haefelin C, Thimme R, Henneke P, Klein R, Paranhos-Baccala G, Depla E, Liang TJ, Blum HE, and Baumert TF. 2005. Uptake and presentation of hepatitis $\mathrm{C}$ virus-like particles by human dendritic cells. Blood 105:3605-3614. 10.1182/blood-2004-05-1952

Beaumont E, and Roingeard P. 2013. Prospects for prophylactic hepatitis C vaccines based on virus-like particles. Hum Vaccin Immunother 9:1112-1118. 10.4161/hv.23900

Biabanikhankahdani R, Alitheen NB, Ho KL, and Tan WS. 2016. pH-responsive Virus-like Nanoparticles with Enhanced Tumour-targeting Ligands for Cancer Drug Delivery. Sci Rep 6:37891. 10.1038/srep37891

Brinkman M, Walter J, Grein S, Thies MJ, Schulz TW, Herrmann M, Reiser CO, and Hess J. 2005. Beneficial therapeutic effects with different particulate structures of murine polyomavirus VP1-coat protein carrying self or non-self CD8 T cell epitopes against murine melanoma. Cancer Immunol Immunother 54:611-622. 10.1007/s00262-004-06550

Castiblanco J, and Anaya JM. 2015. Genetics and vaccines in the era of personalized medicine. Curr Genomics 16:47-59. 10.2174/1389202916666141223220551 
657 Cesana GC, DeRaffele G, Cohen S, Moroziewicz D, Mitcham J, Stoutenburg J, Cheung K, 658 Hesdorffer C, Kim-Schulze S, and Kaufman HL. 2006. Characterization of CD4+CD25+

659

660

661

662

663

664

665

666

667

668

669

670

671

672

673

674

675

676

677

678

679

680

681

682

683

684

685

686

687

688

689

690 regulatory $\mathrm{T}$ cells in patients treated with high-dose interleukin-2 for metastatic melanoma or renal cell carcinoma. $J$ Clin Oncol 24:1169-1177. $10.1200 / \mathrm{JCO} .2005 .03 .6830$

Chang K, and Pastan I. 1996. Molecular cloning of mesothelin, a differentiation antigen present on mesothelium, mesotheliomas, and ovarian cancers. Proc Natl Acad Sci U S A 93:136140 .

Chiosea SI, Williams L, Griffith CC, Thompson LD, Weinreb I, Bauman JE, Luvison A, Roy S, Seethala RR, and Nikiforova MN. 2015. Molecular characterization of apocrine salivary duct carcinoma. Am J Surg Pathol 39:744-752. 10.1097/PAS.0000000000000410

Chroboczek J, Szurgot I, and Szolajska E. 2014. Virus-like particles as vaccine. Acta Biochim Pol 61:531-539.

Crisci E, Barcena J, and Montoya M. 2012. Virus-like particles: the new frontier of vaccines for animal viral infections. Vet Immunol Immunopathol 148:211-225. 10.1016/j.vetimm.2012.04.026

Cubas R, Li M, Chen C, and Yao Q. 2009. Trop2: a possible therapeutic target for late stage epithelial carcinomas. Biochim Biophys Acta 1796:309-314. 10.1016/j.bbcan.2009.08.001

Cubas R, Zhang S, Li M, Chen C, and Yao Q. 2011. Chimeric Trop2 virus-like particles: a potential immunotherapeutic approach against pancreatic cancer. J Immunother 34:251263. 10.1097/CJI.0b013e318209ee72

Cunha AC, Weigle B, Kiessling A, Bachmann M, and Rieber EP. 2006. Tissue-specificity of prostate specific antigens: comparative analysis of transcript levels in prostate and nonprostatic tissues. Cancer Lett 236:229-238. 10.1016/j.canlet.2005.05.021

Cuzick J. 2015. Gardasil 9 joins the fight against cervix cancer. Expert Rev Vaccines 14:10471049. $10.1586 / 14760584.2015 .1051470$

DeFilippis RA, Goodwin EC, Wu L, and DiMaio D. 2003. Endogenous human papillomavirus E6 and E7 proteins differentially regulate proliferation, senescence, and apoptosis in HeLa cervical carcinoma cells. J Virol 77:1551-1563.

Dimberu PM, and Leonhardt RM. 2011. Cancer immunotherapy takes a multi-faceted approach to kick the immune system into gear. Yale J Biol Med 84:371-380.

Ding FX, Wang F, Lu YM, Li K, Wang KH, He XW, and Sun SH. 2009. Multiepitope peptideloaded virus-like particles as a vaccine against hepatitis B virus-related hepatocellular carcinoma. Hepatology 49:1492-1502. 10.1002/hep.22816 
691

692

693

694

695

696

697

698

699

700

701

702

703

704

705

706

707

708

709

710

711

712

713

714

715

716

717

718

719

720

721

722

723

724

725

726

727

Drake DR, 3rd, Moser JM, Hadley A, Altman JD, Maliszewski C, Butz E, and Lukacher AE. 2000. Polyomavirus-infected dendritic cells induce antiviral CD8(+) T lymphocytes. $J$ Virol 74:4093-4101.

Elmowalid GA, Qiao M, Jeong SH, Borg BB, Baumert TF, Sapp RK, Hu Z, Murthy K, and Liang TJ. 2007. Immunization with hepatitis $\mathrm{C}$ virus-like particles results in control of hepatitis C virus infection in chimpanzees. Proc Natl Acad Sci U S A 104:8427-8432. 10.1073/pnas.0702162104

Eriksson M, Andreasson K, Weidmann J, Lundberg K, Tegerstedt K, Dalianis T, and Ramqvist T. 2011. Murine polyomavirus virus-like particles carrying full-length human PSA protect $\mathrm{BALB} / \mathrm{c}$ mice from outgrowth of a PSA expressing tumor. PLoS One 6:e23828. 10.1371/journal.pone.0023828

Ferlay J, Steliarova-Foucher E, Lortet-Tieulent J, Rosso S, Coebergh JW, Comber H, Forman D, and Bray F. 2013. Cancer incidence and mortality patterns in Europe: estimates for 40 countries in 2012. Eur J Cancer 49:1374-1403. 10.1016/j.ejca.2012.12.027

Fong D, Moser P, Krammel C, Gostner JM, Margreiter R, Mitterer M, Gastl G, and Spizzo G. 2008. High expression of TROP2 correlates with poor prognosis in pancreatic cancer. $\mathrm{Br}$ J Cancer 99:1290-1295. 10.1038/sj.bjc.6604677

Frierson HF, Jr., Moskaluk CA, Powell SM, Zhang H, Cerilli LA, Stoler MH, Cathro H, and Hampton GM. 2003. Large-scale molecular and tissue microarray analysis of mesothelin expression in common human carcinomas. Hum Pathol 34:605-609.

Gambhira R, Jagu S, Karanam B, Gravitt PE, Culp TD, Christensen ND, and Roden RB. 2007. Protection of rabbits against challenge with rabbit papillomaviruses by immunization with the $\mathrm{N}$ terminus of human papillomavirus type 16 minor capsid antigen L2. J Virol 81:11585-11592. 10.1128/JVI.01577-07

Garrone P, Fluckiger AC, Mangeot PE, Gauthier E, Dupeyrot-Lacas P, Mancip J, Cangialosi A, Du Chene I, LeGrand R, Mangeot I, Lavillette D, Bellier B, Cosset FL, Tangy F, Klatzmann D, and Dalba C. 2011. A prime-boost strategy using virus-like particles pseudotyped for HCV proteins triggers broadly neutralizing antibodies in macaques. Sci Transl Med 3:94ra71. 10.1126/scitranslmed.3002330

Gheysen D, Jacobs E, de Foresta F, Thiriart C, Francotte M, Thines D, and De Wilde M. 1989. Assembly and release of HIV-1 precursor Pr55gag virus-like particles from recombinant baculovirus-infected insect cells. Cell 59:103-112.

Goldinger SM, Dummer R, Baumgaertner P, Mihic-Probst D, Schwarz K, Hammann-Haenni A, Willers J, Geldhof C, Prior JO, Kundig TM, Michielin O, Bachmann MF, and Speiser DE. 2012. Nano-particle vaccination combined with TLR-7 and -9 ligands triggers memory and effector CD8(+) T-cell responses in melanoma patients. Eur J Immunol 42:30493061. 10.1002/eji.201142361 
728

729

730

731

732

733

734

735

736

737

738

739

740

741

742

743

744

745

746

747

748

749

750

751

752

753

754

755

756

757

758

759

760

761

762

Gostimir M, Bennett S, Moyana T, Sekhon H, and Martel G. 2016. Complete pathological response following neoadjuvant FOLFIRINOX in borderline resectable pancreatic cancer - a case report and review. BMC Cancer 16:786. 10.1186/s12885-016-2821-0

Gould SJ, and Raposo G. 2013. As we wait: coping with an imperfect nomenclature for extracellular vesicles. J Extracell Vesicles 2. 10.3402/jev.v2i0.20389

Graff JN, and Chamberlain ED. 2015. Sipuleucel-T in the treatment of prostate cancer: an evidence-based review of its place in therapy. Core Evid 10:1-10. 10.2147/CE.S54712

Graham SV. 2010. Human papillomavirus: gene expression, regulation and prospects for novel diagnostic methods and antiviral therapies. Future Microbiol 5:1493-1506. 10.2217/fmb.10.107

Gubbels JA, Belisle J, Onda M, Rancourt C, Migneault M, Ho M, Bera TK, Connor J, Sathyanarayana BK, Lee B, Pastan I, and Patankar MS. 2006. Mesothelin-MUC16 binding is a high affinity, N-glycan dependent interaction that facilitates peritoneal metastasis of ovarian tumors. Mol Cancer 5:50. 10.1186/1476-4598-5-50

Guo C, Manjili MH, Subjeck JR, Sarkar D, Fisher PB, and Wang XY. 2013. Therapeutic cancer vaccines: past, present, and future. Adv Cancer Res 119:421-475. 10.1016/B978-0-12407190-2.00007-1

Haynes JR. 2009. Influenza virus-like particle vaccines. Expert Rev Vaccines 8:435-445. 10.1586/erv.09.8

Herzenberg LA, and Tokuhisa T. 1982. Epitope-specific regulation. I. Carrier-specific induction of suppression for IgG anti-hapten antibody responses. J Exp Med 155:1730-1740.

Hjalgrim H, Friborg J, and Melbye M. 2007. The epidemiology of EBV and its association with malignant disease. In: Arvin A, Campadelli-Fiume G, Mocarski E, Moore PS, Roizman B, Whitley R, and Yamanishi K, eds. Human Herpesviruses: Biology, Therapy, and Immunoprophylaxis. Cambridge.

Ho M, Bera TK, Willingham MC, Onda M, Hassan R, FitzGerald D, and Pastan I. 2007. Mesothelin expression in human lung cancer. Clin Cancer Res 13:1571-1575. 10.1158/1078-0432.CCR-06-2161

Howard CR, and Allison LM. 1995. Hepatitis B surface antigen variation and protective immunity. Intervirology 38:35-40.

Huber B, Schellenbacher C, Jindra C, Fink D, Shafti-Keramat S, and Kirnbauer R. 2015. A chimeric 18L1-45RG1 virus-like particle vaccine cross-protects against oncogenic alpha7 human papillomavirus types. PLoS One 10:e0120152. 10.1371/journal.pone.0120152

Jegerlehner A, Wiesel M, Dietmeier K, Zabel F, Gatto D, Saudan P, and Bachmann MF. 2010. Carrier induced epitopic suppression of antibody responses induced by virus-like 
765

766

767

768

769

770

771

772

773

774

775

776

777

778

779

780

781

782

783

784

785

786

787

788

789

790

791

792

793

794

795

796

797

798

799

particles is a dynamic phenomenon caused by carrier-specific antibodies. Vaccine 28:5503-5512. 10.1016/j.vaccine.2010.02.103

Jemon K, Young V, Wilson M, McKee S, Ward V, Baird M, Young S, and Hibma M. 2013. An enhanced heterologous virus-like particle for human papillomavirus type 16 tumour immunotherapy. PLoS One 8:e66866. 10.1371/journal.pone.0066866

Jennings GT, and Bachmann MF. 2008. The coming of age of virus-like particle vaccines. Biol Chem 389:521-536.

Jeong SH, Qiao M, Nascimbeni M, Hu Z, Rehermann B, Murthy K, and Liang TJ. 2004. Immunization with hepatitis $\mathrm{C}$ virus-like particles induces humoral and cellular immune responses in nonhuman primates. $J$ Virol 78:6995-7003. 10.1128/JVI.78.13.69957003.2004

Jochum S, Ruiss R, Moosmann A, Hammerschmidt W, and Zeidler R. 2012. RNAs in EpsteinBarr virions control early steps of infection. Proc Natl Acad Sci U S A 109:E1396-1404. 10.1073/pnas.1115906109

Kazaks A, Balmaks R, Voronkova T, Ose V, and Pumpens P. 2008. Melanoma vaccine candidates from chimeric hepatitis B core virus-like particles carrying a tumor-associated MAGE-3 epitope. Biotechnol J 3:1429-1436. 10.1002/biot.200800160

Khan KH. 2013. Gene expression in Mammalian cells and its applications. Adv Pharm Bull 3:257-263. 10.5681/apb.2013.042

Kim Y, Ejaz A, Tayal A, Spolverato G, Bridges JF, Anders RA, and Pawlik TM. 2014. Temporal trends in population-based death rates associated with chronic liver disease and liver cancer in the United States over the last 30 years. Cancer 120:3058-3065. 10.1002/cncr.28843

Kjerrulf M, Lowenadler B, Svanholm C, and Lycke N. 1997. Tandem repeats of T helper epitopes enhance immunogenicity of fusion proteins by promoting processing and presentation. Mol Immunol 34:599-608.

Klamp T, Schumacher J, Huber G, Kuhne C, Meissner U, Selmi A, Hiller T, Kreiter S, Markl J, Tureci O, and Sahin U. 2011. Highly specific auto-antibodies against claudin-18 isoform 2 induced by a chimeric $\mathrm{HBcAg}$ virus-like particle vaccine kill tumor cells and inhibit the growth of lung metastases. Cancer Res 71:516-527. 10.1158/0008-5472.CAN-10-2292

Koie T, Mitsuzuka K, Yoneyama T, Narita S, Kawamura S, Kaiho Y, Tsuchiya N, Tochigi T, Habuchi T, Arai Y, Ohyama C, Yoneyama T, and Tobisawa Y. 2015. Prostate-specific antigen density predicts extracapsular extension and increased risk of biochemical recurrence in patients with high-risk prostate cancer who underwent radical prostatectomy. Int J Clin Oncol 20:176-181. 10.1007/s10147-014-0696-0

Kourembanas S. 2015. Exosomes: vehicles of intercellular signaling, biomarkers, and vectors of cell therapy. Annu Rev Physiol 77:13-27. 10.1146/annurev-physiol-021014-071641 
800

801

802

803

804

805

806

807

808

809

810

811

812

813

814

815

816

817

818

819

820

821

822

823

824

825

826

827

828

829

830

831

832

Kuang DM, Zhao Q, Peng C, Xu J, Zhang JP, Wu C, and Zheng L. 2009. Activated monocytes in peritumoral stroma of hepatocellular carcinoma foster immune privilege and disease progression through PD-L1. J Exp Med 206:1327-1337. 10.1084/jem.20082173

Kushnir N, Streatfield SJ, and Yusibov V. 2012. Virus-like particles as a highly efficient vaccine platform: diversity of targets and production systems and advances in clinical development. Vaccine 31:58-83. 10.1016/j.vaccine.2012.10.083

Laheru D, and Jaffee EM. 2005. Immunotherapy for pancreatic cancer - science driving clinical progress. Nat Rev Cancer 5:459-467. 10.1038/nrc1630

Lavanchy D. 2005. Worldwide epidemiology of HBV infection, disease burden, and vaccine prevention. J Clin Virol 34 Suppl 1:S1-3.

Lechmann M, Murata K, Satoi J, Vergalla J, Baumert TF, and Liang TJ. 2001. Hepatitis C viruslike particles induce virus-specific humoral and cellular immune responses in mice. Hepatology 34:417-423. 10.1053/jhep.2001.26523

Lee KW, Tey BT, Ho KL, Tejo BA, and Tan WS. 2012. Nanoglue: an alternative way to display cell-internalizing peptide at the spikes of hepatitis B virus core nanoparticles for celltargeting delivery. Mol Pharm 9:2415-2423. 10.1021/mp200389t

Li K, Peers-Adams A, Win SJ, Scullion S, Wilson M, Young VL, Jennings P, Ward VK, Baird MA, and Young SL. 2013. Antigen incorporated in virus-like particles is delivered to specific dendritic cell subsets that induce an effective antitumor immune response in vivo. J Immunother 36:11-19. 10.1097/CJI.0b013e3182787f5e

Li M, Bharadwaj U, Zhang R, Zhang S, Mu H, Fisher WE, Brunicardi FC, Chen C, and Yao Q. 2008. Mesothelin is a malignant factor and therapeutic vaccine target for pancreatic cancer. Mol Cancer Ther 7:286-296. 10.1158/1535-7163.MCT-07-0483

Liu JK. 2014. Anti-cancer vaccines - a one-hit wonder? Yale J Biol Med 87:481-489.

Ljubojevic S, and Skerlev M. 2014. HPV-associated diseases. Clin Dermatol 32:227-234. 10.1016/j.clindermatol.2013.08.007

Lollini PL, Cavallo F, Nanni P, and Forni G. 2006. Vaccines for tumour prevention. Nat Rev Cancer 6:204-216. 10.1038/nrc1815

Ly KN, Xing J, Klevens RM, Jiles RB, Ward JW, and Holmberg SD. 2012. The increasing burden of mortality from viral hepatitis in the United States between 1999 and 2007. Ann Intern Med 156:271-278. 10.7326/0003-4819-156-4-201202210-00004

Ma B, Roden R, and Wu TC. 2010. Current status of human papillomavirus vaccines. J Formos Med Assoc 109:481-483. 
833

834

835

836

837

838

839

840

841

842

843

844

845

846

847

848

849

850

851

852

853

854

855

856

857

858

859

860

861

862

863

864

865

866

867

868

869

Madrid-Marina V, Torres-Poveda K, Lopez-Toledo G, and Garcia-Carranca A. 2009. Advantages and disadvantages of current prophylactic vaccines against HPV. Arch Med Res 40:471-477. 10.1016/j.arcmed.2009.08.005

Maecker HT, Umetsu DT, DeKruyff RH, and Levy S. 1998. Cytotoxic T cell responses to DNA vaccination: dependence on antigen presentation via class II MHC. J Immunol 161:65326536.

Markopoulos C, Tsaroucha AK, Kouskos E, Mantas D, Antonopoulou Z, and Karvelis S. 2009. Impact of breast cancer surgery on the self-esteem and sexual life of female patients. $J$ Int Med Res 37:182-188.

Martin Caballero J, Garzon A, Gonzalez-Cintado L, Kowalczyk W, Jimenez Torres I, Calderita G, Rodriguez M, Gondar V, Bernal JJ, Ardavin C, Andreu D, Zurcher T, and von Kobbe C. 2012. Chimeric infectious bursal disease virus-like particles as potent vaccines for eradication of established HPV-16 E7-dependent tumors. PLoS One 7:e52976. 10.1371/journal.pone.0052976

McCarthy EF. 2006. The toxins of William B. Coley and the treatment of bone and soft-tissue sarcomas. Iowa Orthop J 26:154-158.

McKee SJ, Young VL, Clow F, Hayman CM, Baird MA, Hermans IF, Young SL, and Ward VK. 2012. Virus-like particles and alpha-galactosylceramide form a self-adjuvanting composite particle that elicits anti-tumor responses. J Control Release 159:338-345. 10.1016/j.jconrel.2012.02.015

Melo SA, Sugimoto H, O'Connell JT, Kato N, Villanueva A, Vidal A, Qiu L, Vitkin E, Perelman LT, Melo CA, Lucci A, Ivan C, Calin GA, and Kalluri R. 2014. Cancer exosomes perform cell-independent microRNA biogenesis and promote tumorigenesis. Cancer Cell 26:707-721. 10.1016/j.ccell.2014.09.005

Meza-Junco J, Au HJ, and Sawyer MB. 2011. Critical appraisal of trastuzumab in treatment of advanced stomach cancer. Cancer Manag Res 3:57-64. 10.2147/CMR.S12698

Micallef JM, Kaldor JM, and Dore GJ. 2006. Spontaneous viral clearance following acute hepatitis C infection: a systematic review of longitudinal studies. $J$ Viral Hepat 13:34-41. 10.1111/j.1365-2893.2005.00651.x

Msaouel P, Pissimissis N, Halapas A, and Koutsilieris M. 2008. Mechanisms of bone metastasis in prostate cancer: clinical implications. Best Pract Res Clin Endocrinol Metab 22:341355. 10.1016/j.beem.2008.01.011

Murata K, Lechmann M, Qiao M, Gunji T, Alter HJ, and Liang TJ. 2003. Immunization with hepatitis $\mathrm{C}$ virus-like particles protects mice from recombinant hepatitis $\mathrm{C}$ virus-vaccinia infection. Proc Natl Acad Sci U S A 100:6753-6758. 10.1073/pnas.1131929100

Narayanan DL, Saladi RN, and Fox JL. 2010. Ultraviolet radiation and skin cancer. Int $J$ Dermatol 49:978-986. 10.1111/j.1365-4632.2010.04474.x 
870

871

872

873

874

875

876

877

878

879

880

881

882

883

884

885

886

887

888

889

890

891

892

893

894

895

896

897

898

899

900

901

902

903

904

905

Noad R, and Roy P. 2003. Virus-like particles as immunogens. Trends Microbiol 11:438-444.

Nolte-'t Hoen E, Cremer T, Gallo RC, and Margolis LB. 2016. Extracellular vesicles and viruses: Are they close relatives? Proc Natl Acad Sci $U$ S A 113:9155-9161. $10.1073 /$ pnas. 1605146113

Nolte-'t Hoen EN, Buschow SI, Anderton SM, Stoorvogel W, and Wauben MH. 2009. Activated T cells recruit exosomes secreted by dendritic cells via LFA-1. Blood 113:1977-1981. 10.1182/blood-2008-08-174094

Nour NM. 2009. Cervical cancer: a preventable death. Rev Obstet Gynecol 2:240-244.

Oberstein PE, and Olive KP. 2013. Pancreatic cancer: why is it so hard to treat? Therap Adv Gastroenterol 6:321-337. 10.1177/1756283X13478680

Ogembo JG, Muraswki MR, McGinnes LW, Parcharidou A, Sutiwisesak R, Tison T, Avendano J, Agnani D, Finberg RW, Morrison TG, and Fingeroth JD. 2015. A chimeric EBV gp350/220-based VLP replicates the virion B-cell attachment mechanism and elicits long-lasting neutralizing antibodies in mice. J Transl Med 13:50. 10.1186/s12967-0150415-2

Ohno S, Drummen GP, and Kuroda M. 2016. Focus on Extracellular Vesicles: Development of Extracellular Vesicle-Based Therapeutic Systems. Int $J$ Mol Sci 17:172. 10.3390/ijms 17020172

Ott PA, Hu Z, Keskin DB, Shukla SA, Sun J, Bozym DJ, Zhang W, Luoma A, Giobbie-Hurder A, Peter L, Chen C, Olive O, Carter TA, Li S, Lieb DJ, Eisenhaure T, Gjini E, Stevens J, Lane WJ, Javeri I, Nellaiappan K, Salazar AM, Daley H, Seaman M, Buchbinder EI, Yoon CH, Harden M, Lennon N, Gabriel S, Rodig SJ, Barouch DH, Aster JC, Getz G, Wucherpfennig K, Neuberg D, Ritz J, Lander ES, Fritsch EF, Hacohen N, and Wu CJ. 2017. An immunogenic personal neoantigen vaccine for patients with melanoma. Nature 547:217-221. 10.1038/nature22991

Parkin DM. 2006. The global health burden of infection-associated cancers in the year 2002. Int J Cancer 118:3030-3044. 10.1002/ijc.21731

Pastrana DV, Gambhira R, Buck CB, Pang YY, Thompson CD, Culp TD, Christensen ND, Lowy DR, Schiller JT, and Roden RB. 2005. Cross-neutralization of cutaneous and mucosal Papillomavirus types with anti-sera to the amino terminus of L2. Virology 337:365-372. 10.1016/j.virol.2005.04.011

Patel JM, Kim MC, Vartabedian VF, Lee YN, He S, Song JM, Choi HJ, Yamanaka S, Amaram N, Lukacher A, Montemagno CD, Compans RW, Kang SM, and Selvaraj P. 2015a. Protein transfer-mediated surface engineering to adjuvantate virus-like nanoparticles for enhanced anti-viral immune responses. Nanomedicine 11:1097-1107. 10.1016/j.nano.2015.02.008 
906

907

908

909

910

911

912

913

914

915

916

917

918

919

920

921

922

923

924

925

926

927

928

929

930

931

932

933

934

935

936

937

938

939

940

941

942

Patel JM, Vartabedian VF, Kim MC, He S, Kang SM, and Selvaraj P. 2015b. Influenza virus-like particles engineered by protein transfer with tumor-associated antigens induces protective antitumor immunity. Biotechnol Bioeng 112:1102-1110. 10.1002/bit.25537

Pestka JM, Zeisel MB, Blaser E, Schurmann P, Bartosch B, Cosset FL, Patel AH, Meisel H, Baumert J, Viazov S, Rispeter K, Blum HE, Roggendorf M, and Baumert TF. 2007. Rapid induction of virus-neutralizing antibodies and viral clearance in a single-source outbreak of hepatitis C. Proc Natl Acad Sci $U$ S A 104:6025-6030. 10.1073/pnas.0607026104

Pineo CB, Hitzeroth, II, and Rybicki EP. 2013. Immunogenic assessment of plant-produced human papillomavirus type 16 L1/L2 chimaeras. Plant Biotechnol J 11:964-975. 10.1111/pbi.12089

Pleckaityte M, Bremer CM, Gedvilaite A, Kucinskaite-Kodze I, Glebe D, and Zvirbliene A. 2015. Construction of polyomavirus-derived pseudotype virus-like particles displaying a functionally active neutralizing antibody against hepatitis B virus surface antigen. $B M C$ Biotechnol 15:85. 10.1186/s12896-015-0203-3

Poynard T, Yuen MF, Ratziu V, and Lai CL. 2003. Viral hepatitis C. Lancet 362:2095-2100.

Psyrri A, DeFilippis RA, Edwards AP, Yates KE, Manuelidis L, and DiMaio D. 2004. Role of the retinoblastoma pathway in senescence triggered by repression of the human papillomavirus E7 protein in cervical carcinoma cells. Cancer Res 64:3079-3086.

Qiao M, Murata K, Davis AR, Jeong SH, and Liang TJ. 2003. Hepatitis C virus-like particles combined with novel adjuvant systems enhance virus-specific immune responses. Hepatology 37:52-59. 10.1053/jhep.2003.50000

Raposo G, Nijman HW, Stoorvogel W, Liejendekker R, Harding CV, Melief CJ, and Geuze HJ. 1996. B lymphocytes secrete antigen-presenting vesicles. J Exp Med 183:1161-1172.

Rhim AD, Mirek ET, Aiello NM, Maitra A, Bailey JM, McAllister F, Reichert M, Beatty GL, Rustgi AK, Vonderheide RH, Leach SD, and Stanger BZ. 2012. EMT and dissemination precede pancreatic tumor formation. Cell 148:349-361. 10.1016/j.cell.2011.11.025

Ross JS, Fletcher JA, Linette GP, Stec J, Clark E, Ayers M, Symmans WF, Pusztai L, and Bloom KJ. 2003. The Her-2/neu gene and protein in breast cancer 2003: biomarker and target of therapy. Oncologist 8:307-325.

Ruiss R, Jochum S, Wanner G, Reisbach G, Hammerschmidt W, and Zeidler R. 2011. A viruslike particle-based Epstein-Barr virus vaccine. $J$ Virol 85:13105-13113. 10.1128/JVI.05598-11

Ruiz-Tachiquin ME, Valdez-Salazar HA, Juarez-Barreto V, Dehesa-Violante M, Torres J, Munoz-Hernandez O, and Alvarez-Munoz MT. 2007. Molecular analysis of hepatitis B virus "a" determinant in asymptomatic and symptomatic Mexican carriers. Virol $J$ 4:6. 10.1186/1743-422X-4-6 
943
Ruschoff J, Hanna W, Bilous M, Hofmann M, Osamura RY, Penault-Llorca F, van de Vijver M, and Viale G. 2012. HER2 testing in gastric cancer: a practical approach. Mod Pathol 25:637-650. 10.1038/modpathol.2011.198

Rynda-Apple A, Patterson DP, and Douglas T. 2014. Virus-like particles as antigenic nanomaterials for inducing protective immune responses in the lung. Nanomedicine (Lond) 9:1857-1868. 10.2217/nnm.14.107

Sannino G, Armbruster N, Bodenhofer M, Haerle U, Behrens D, Buchholz M, Rothbauer U, Sipos B, and Schmees C. 2016. Role of BCL9L in transforming growth factor-beta (TGFbeta)-induced epithelial-to-mesenchymal-transition (EMT) and metastasis of pancreatic cancer. Oncotarget. 10.18632/oncotarget. 12455

Santin AD, Bellone S, Roman JJ, McKenney JK, and Pecorelli S. 2008. Trastuzumab treatment in patients with advanced or recurrent endometrial carcinoma overexpressing HER2/neu. Int J Gynaecol Obstet 102:128-131. 10.1016/j.ijgo.2008.04.008

Savelyeva N, Munday R, Spellerberg MB, Lomonossoff GP, and Stevenson FK. 2001. Plant viral genes in DNA idiotypic vaccines activate linked CD4+ T-cell mediated immunity against B-cell malignancies. Nat Biotechnol 19:760-764. 10.1038/90816

Schaefer S, Seifer M, Grimmsmann T, Fink L, Wenderhold S, Hohne MW, and Gerlich WH. 1998. Properties of tumour suppressor p53 in murine hepatocyte lines transformed by hepatitis B virus X protein. J Gen Virol 79 ( Pt 4):767-777. 10.1099/0022-1317-79-4-767

Schellenbacher C, Kwak K, Fink D, Shafti-Keramat S, Huber B, Jindra C, Faust H, Dillner J, Roden RB, and Kirnbauer R. 2013. Efficacy of RG1-VLP vaccination against infections with genital and cutaneous human papillomaviruses. $J$ Invest Dermatol 133:2706-2713. $10.1038 /$ jid.2013.253

Schirrmacher V, and Fournier P. 2010. Danger signals in tumor cells: a risk factor for autoimmune disease? Expert Rev Vaccines 9:347-350. 10.1586/erv.10.15

Schlom J. 2012. Therapeutic cancer vaccines: current status and moving forward. J Natl Cancer Inst 104:599-613. 10.1093/jnci/djs033

Shashidharamurthy R, Bozeman EN, Patel J, Kaur R, Meganathan J, and Selvaraj P. 2012. Immunotherapeutic strategies for cancer treatment: a novel protein transfer approach for cancer vaccine development. Med Res Rev 32:1197-1219. 10.1002/med.20237

Simoes MC, Sousa JJ, and Pais AA. 2015. Skin cancer and new treatment perspectives: a review. Cancer Lett 357:8-42. 10.1016/j.canlet.2014.11.001

Somi MH, Etemadi J, Ghojazadeh M, Farhang S, Faramarzi M, Foroutan S, and Soleimanpour M. 2014. Risk factors of HCV seroconversion in hemodialysis patients in tabriz, iran. Hepat Mon 14:e17417. 10.5812/hepatmon. 17417 
978

979

980

981

982

983

984

985

986

987

988

989

990

991

992

993

994

995

996

997

998

999

1000

1001

1002

1003

1004

1005

1006

1007

1008

1009

1010

1011

1012

1013

1014

Steinbach D, Onda M, Voigt A, Dawczynski K, Wittig S, Hassan R, Gruhn B, and Pastan I. 2007. Mesothelin, a possible target for immunotherapy, is expressed in primary AML cells. Eur J Haematol 79:281-286. 10.1111/j.1600-0609.2007.00928.x

Steinmetz NF, Mertens ME, Taurog RE, Johnson JE, Commandeur U, Fischer R, and Manchester M. 2010. Potato virus $\mathrm{X}$ as a novel platform for potential biomedical applications. Nano Lett 10:305-312. 10.1021/n19035753

Stickney Z, Losacco J, McDevitt S, Zhang Z, and Lu B. 2016. Development of exosome surface display technology in living human cells. Biochem Biophys Res Commun 472:53-59. 10.1016/j.bbrc.2016.02.058

Strassburg MA. 1982. The global eradication of smallpox. Am J Infect Control 10:53-59.

Su Q, Schroder CH, Hofmann WJ, Otto G, Pichlmayr R, and Bannasch P. 1998. Expression of hepatitis B virus X protein in HBV-infected human livers and hepatocellular carcinomas. Hepatology 27:1109-1120. 10.1002/hep.510270428

Tan WS, and Ho KL. 2014. Phage display creates innovative applications to combat hepatitis B virus. World J Gastroenterol 20:11650-11670. 10.3748/wjg.v20.i33.11650

Tegerstedt K, Franzen A, Ramqvist T, and Dalianis T. 2007. Dendritic cells loaded with polyomavirus VP1/VP2Her2 virus-like particles efficiently prevent outgrowth of a Her2/neu expressing tumor. Cancer Immunol Immunother 56:1335-1344. $10.1007 / \mathrm{s} 00262-007-0281-8$

Tegerstedt K, Lindencrona JA, Curcio C, Andreasson K, Tullus C, Forni G, Dalianis T, Kiessling R, and Ramqvist T. 2005. A single vaccination with polyomavirus VP1/VP2Her2 virus-like particles prevents outgrowth of HER-2/neu-expressing tumors. Cancer Res 65:5953-5957. 10.1158/0008-5472.CAN-05-0335

Terpe K. 2006. Overview of bacterial expression systems for heterologous protein production: from molecular and biochemical fundamentals to commercial systems. Appl Microbiol Biotechnol 72:211-222. 10.1007/s00253-006-0465-8

Thompson MP, and Kurzrock R. 2004. Epstein-Barr virus and cancer. Clin Cancer Res 10:803821.

Tjalma WA, Fiander A, Reich O, Powell N, Nowakowski AM, Kirschner B, Koiss R, O'Leary J, Joura EA, Rosenlund M, Colau B, Schledermann D, Kukk K, Damaskou V, Repanti M, Vladareanu R, Kolomiets L, Savicheva A, Shipitsyna E, Ordi J, Molijn A, Quint W, Raillard A, Rosillon D, De Souza SC, Jenkins D, Holl K, and Group HSS. 2013. Differences in human papillomavirus type distribution in high-grade cervical intraepithelial neoplasia and invasive cervical cancer in Europe. Int J Cancer 132:854867. 10.1002/ijc. 27713

Tominaga N, Yoshioka Y, and Ochiya T. 2015. A novel platform for cancer therapy using extracellular vesicles. Adv Drug Deliv Rev 95:50-55. 10.1016/j.addr.2015.10.002 
1015 Tomura M, Yu WG, Ahn HJ, Yamashita M, Yang YF, Ono S, Hamaoka T, Kawano T,

1016

1017

1018

1019

1020

1021

1022

1023

1024

1025

1026

1027

1028

1029

1030

1031

1032

1033

1034

1035

1036

1037

1038

1039

1040

1041

1042

1043

1044

1045

1046

1047

1048

1049

1050

1051

Taniguchi M, Koezuka Y, and Fujiwara H. 1999. A novel function of Valpha14+CD4+NKT cells: stimulation of IL-12 production by antigen-presenting cells in the innate immune system. J Immunol 163:93-101.

Torre LA, Bray F, Siegel RL, Ferlay J, Lortet-Tieulent J, and Jemal A. 2015. Global cancer statistics, 2012. CA Cancer J Clin 65:87-108. 10.3322/caac.21262

Tyler M, Tumban E, and Chackerian B. 2014. Second-generation prophylactic HPV vaccines: successes and challenges. Expert Rev Vaccines 13:247-255. $10.1586 / 14760584.2014 .865523$

Vietheer PT, Boo I, Drummer HE, and Netter HJ. 2007. Immunizations with chimeric hepatitis B virus-like particles to induce potential anti-hepatitis $\mathrm{C}$ virus neutralizing antibodies. Antivir Ther 12:477-487.

Wang B, Kuroiwa JM, He LZ, Charalambous A, Keler T, and Steinman RM. 2009. The human cancer antigen mesothelin is more efficiently presented to the mouse immune system when targeted to the DEC-205/CD205 receptor on dendritic cells. Ann N Y Acad Sci 1174:6-17. 10.1111/j.1749-6632.2009.04933.x

Wang JW, and Roden RB. 2013. Virus-like particles for the prevention of human papillomavirus-associated malignancies. Expert Rev Vaccines 12:129-141. 10.1586/erv.12.151

Wang M, Zhao J, Zhang L, Wei F, Lian Y, Wu Y, Gong Z, Zhang S, Zhou J, Cao K, Li X, Xiong W, Li G, Zeng Z, and Guo C. 2017. Role of tumor microenvironment in tumorigenesis. $J$ Cancer 8:761-773. 10.7150/jca.17648

Williams CB, Yeh ES, and Soloff AC. 2016. Tumor-associated macrophages: unwitting accomplices in breast cancer malignancy. NPJ Breast Cancer 2. $10.1038 /$ npjbcancer.2015.25

Wilt TJ, and Ahmed HU. 2013. Prostate cancer screening and the management of clinically localized disease. $B M J 346: f 325$. 10.1136/bmj.f325

Wolfers J, Lozier A, Raposo G, Regnault A, Thery C, Masurier C, Flament C, Pouzieux S, Faure F, Tursz T, Angevin E, Amigorena S, and Zitvogel L. 2001. Tumor-derived exosomes are a source of shared tumor rejection antigens for CTL cross-priming. Nat Med 7:297-303. $10.1038 / 85438$

Wurdinger T, Gatson NN, Balaj L, Kaur B, Breakefield XO, and Pegtel DM. 2012. Extracellular vesicles and their convergence with viral pathways. Adv Virol 2012:767694. $10.1155 / 2012 / 767694$

Yan D, Wei YQ, Guo HC, and Sun SQ. 2015. The application of virus-like particles as vaccines and biological vehicles. Appl Microbiol Biotechnol 99:10415-10432. 10.1007/s00253015-7000-8 
1052

1053

1054

1055

1056

1057

1058

1059

1060

1061

1062

1063

1064

1065

1066

1067

1068

1069

1070

1071

1072

1073

1074

1075

1076

1077

1078

1079

1080
Yao Q, Kuhlmann FM, Eller R, Compans RW, and Chen C. 2000. Production and characterization of simian--human immunodeficiency virus-like particles. AIDS Res Hum Retroviruses 16:227-236. 10.1089/088922200309322

Ye L, Dong N, Wang Q, Xu Z, Cai N, Wang H, and Zhang X. 2008. Progressive changes in hepatoma cells stably transfected with hepatitis B virus X gene. Intervirology 51:50-58. $10.1159 / 000120289$

Yim EK, and Park JS. 2005. The role of HPV E6 and E7 oncoproteins in HPV-associated cervical carcinogenesis. Cancer Res Treat 37:319-324. 10.4143/crt.2005.37.6.319

Yong CY, Yeap SK, Goh ZH, Ho KL, Omar AR, and Tan WS. 2015a. Induction of humoral and cell-mediated immune responses by hepatitis B virus epitope displayed on the virus-like particles of prawn nodavirus. Appl Environ Microbiol 81:882-889. 10.1128/AEM.0369514

Yong CY, Yeap SK, Ho KL, Omar AR, and Tan WS. 2015b. Potential recombinant vaccine against influenza A virus based on M2e displayed on nodaviral capsid nanoparticles. Int $J$ Nanomedicine 10:2751-2763. 10.2147/IJN.S77405

Zhang S, Yong LK, Li D, Cubas R, Chen C, and Yao Q. 2013. Mesothelin virus-like particle immunization controls pancreatic cancer growth through CD8+ $\mathrm{T}$ cell induction and reduction in the frequency of $\mathrm{CD} 4+$ foxp3+ ICOS- regulatory $\mathrm{T}$ cells. PLoS One 8:e68303. 10.1371/journal.pone.0068303

Zhang Y, Song S, Liu C, Wang Y, Xian X, He Y, Wang J, Liu F, and Sun S. 2007. Generation of chimeric $\mathrm{HBc}$ proteins with epitopes in E.coli: formation of virus-like particles and a potent inducer of antigen-specific cytotoxic immune response and anti-tumor effect in vivo. Cell Immunol 247:18-27. 10.1016/j.cellimm.2007.07.003

Zhu X, Badawi M, Pomeroy S, Sutaria DS, Xie Z, Baek A, Jiang J, Elgamal OA, Mo X, Perle K, Chalmers J, Schmittgen TD, and Phelps MA. 2017. Comprehensive toxicity and immunogenicity studies reveal minimal effects in mice following sustained dosing of extracellular vesicles derived from HEK293T cells. J Extracell Vesicles 6:1324730. $10.1080 / 20013078.2017 .1324730$ 


\section{Figure 1}

A schematic diagram of virus-like particles (VLPs) production using different approaches

a) Production of non-enveloped chimeric VLPs using genetic alteration. Viral structural protein is fused with a foreign antigen via genetic engineering followed by the expression of the chimeric protein in a suitable host system. b) Production of non-enveloped chimeric VLPs by chemical conjugation. Non-enveloped VLPs are produced by expressing a viral structural protein, and surface decoration of the VLPs is achieved by conjugating a foreign antigen to the VLPs, and c) production of enveloped chimeric VLPs by the protein transfer approach. Enveloped VLPs are produced by expressing the viral proteins in suitable host cells followed by incubating with the glycosylphosphatidylinositol (GPI)-anchored proteins. The foreign antigens are then transferred to the lipid bilayer of the VLPS. 
a)

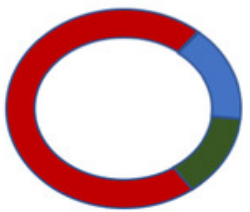

Vector encoding engineered viral capsid
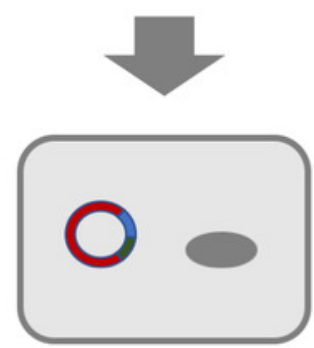

Introduce the recombinant plasmid into host cells.
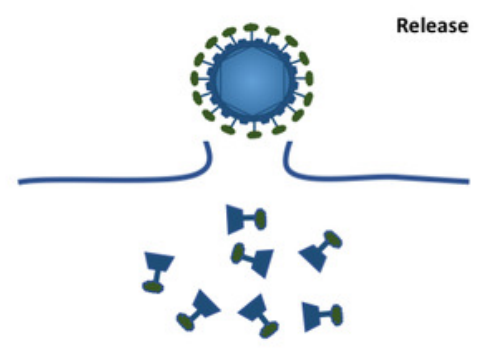

Self-assembly

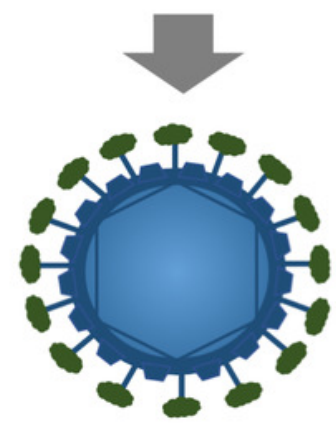

Chimeric VLP b)

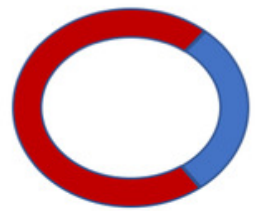

Vector encoding viral capsid
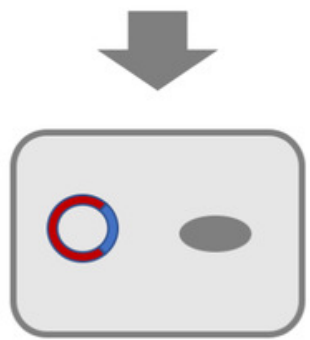

Introduce the recombinant plasmid into host cells.

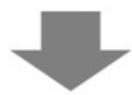

c)

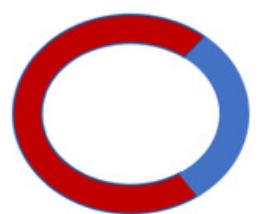

Vector encoding viral capsid

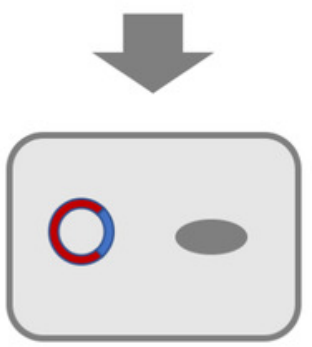

Introduce the recombinant plasmid into host cells.

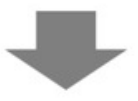

Budding

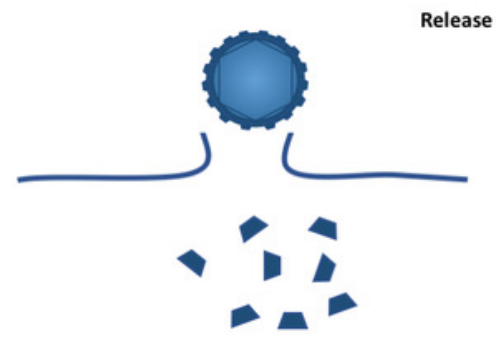

Self-assembly
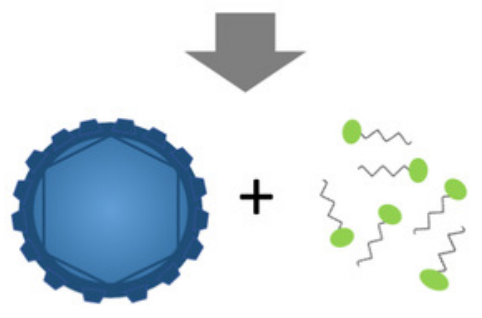

Chemical conjugation of the antigenlinker to the non-enveloped VLP

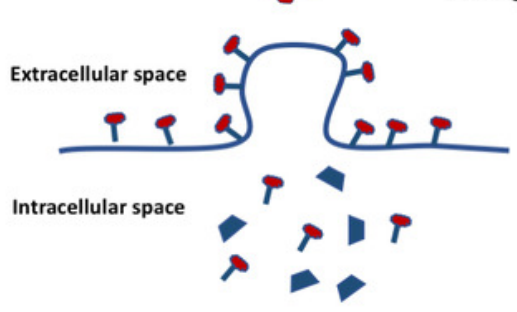

Self-assembly

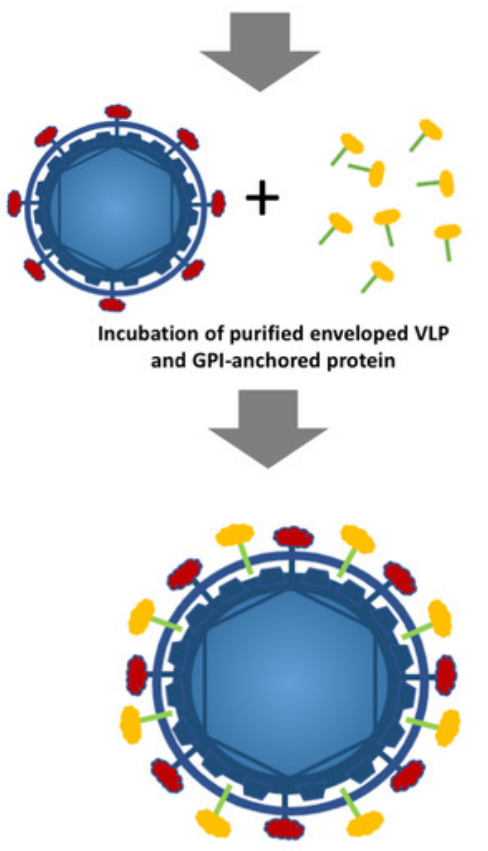




\section{Figure 2}

A schematic diagram of virus-like particle (VLP) in triggering specific immune responses against tumor cells

Chimeric VLPs displaying tumor antigen (red oval) on their surface are administered into an animal model. Tumor antigen is taken up, processed, and presented by dendritic cells (DCs) to respective T cells. Presentation of tumor antigen by DCs converts naïve cytotoxic and helper $T$ cells into cytotoxic $\left(T_{c}\right)$ and effector helper (Th) T cells, respectively. $T_{c}$ cells (red triangles) kill tumor cells by releasing cytotoxic proteins, such as granzyme and perforin. $\mathrm{Th}_{1}$ cells support the activation of $T_{c}$ cells by releasing interleukin-2 (IL-2) and interferon gamma (IFNY), whereas $\mathrm{Th}_{2}$ cells stimulate B cells to produce tumor antigen-specific antibodies, which are capable to bind and mark (red triangles) tumor cells for effective killing by natural killer (NK) cells and phagocytes.
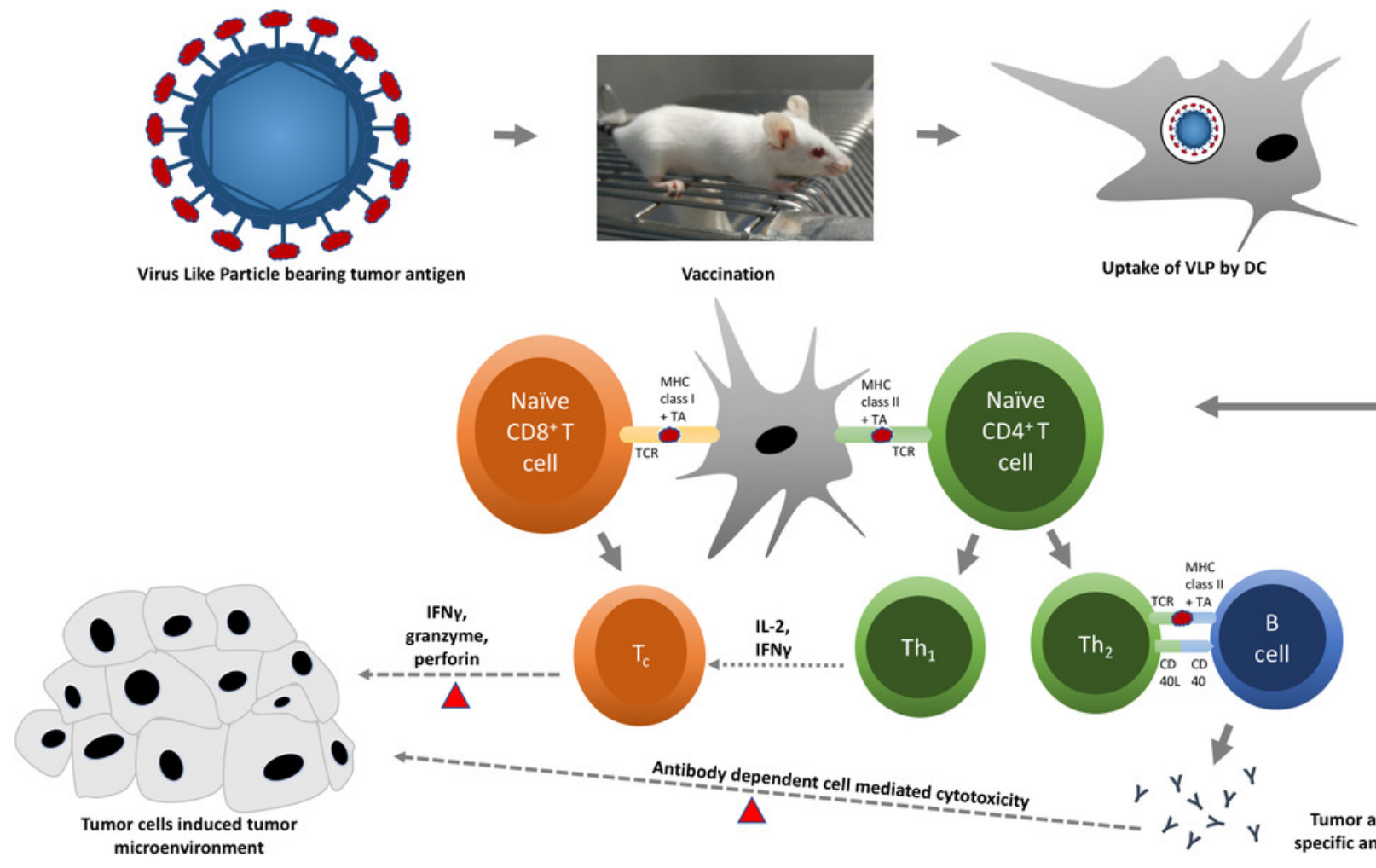

Naïve

$\mathrm{CD}^{+} \mathrm{T}$

cell

ptake of VLP by DC

microenvironment
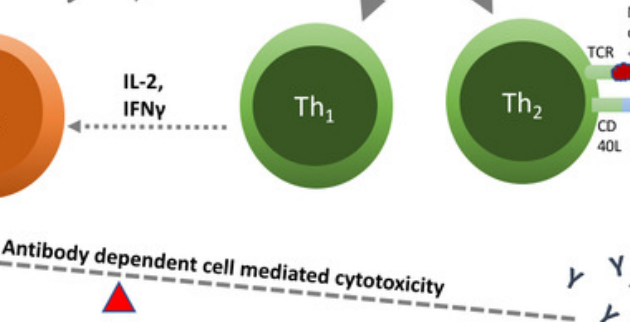

cell

orin
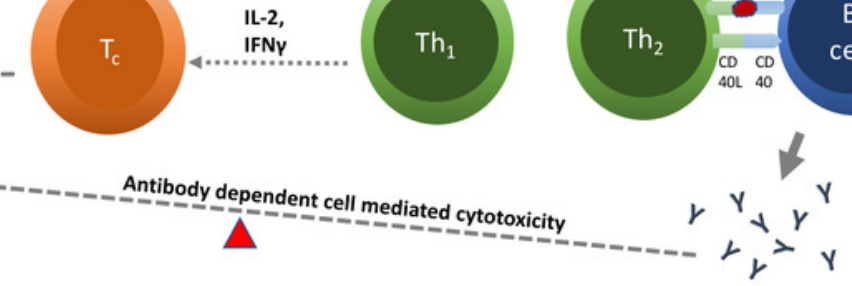

Tumor antigen specific antibodies 
Table $\mathbf{1}$ (on next page)

Oncoviruses and associated cancers 
Table 1: Oncoviruses and associated cancers

\begin{tabular}{|c|c|c|c|c|}
\hline Virus & Oncoviruses associated cancers & $\begin{array}{l}\text { Percentage of the } \\
\text { cancers caused }(\%)\end{array}$ & $\begin{array}{l}\text { Mechanism of } \\
\text { Carcinogenesis }\end{array}$ & Reference \\
\hline HBV & Hepatocellular carcinoma & 3.1 & Chronic inflammation & $\begin{array}{l}\text { (de Martel \& Franceschi } \\
\text { 2009; Parkin 2006) }\end{array}$ \\
\hline $\mathrm{HCV}$ & Hepatocellular carcinoma & 1.8 & Chronic inflammation & $\begin{array}{l}\text { (de Martel \& Franceschi } \\
\text { 2009; Parkin 2006) }\end{array}$ \\
\hline HPV & $\begin{array}{l}\text { Cervical, vulva, vagina, penis, anus and } \\
\text { oropharynx cancers. }\end{array}$ & 5.2 & $\begin{array}{l}\text { Direct carcinogens act via } \\
\text { expression of viral } \\
\text { oncoproteins }\end{array}$ & $\begin{array}{l}\text { (Parkin 2006; Yim \& } \\
\text { Park 2005) }\end{array}$ \\
\hline EBV & $\begin{array}{l}\text { Burkitt's lymphoma, Hodgkin } \\
\text { lymphoma, B cell lymphoma, } \\
\text { nasopharyngeal carcinoma, gastric and } \\
\text { sporadic carcinoma. }\end{array}$ & $1-2$ & $\begin{array}{l}\text { Direct carcinogens act via } \\
\text { expression of viral } \\
\text { oncoproteins }\end{array}$ & $\begin{array}{l}\text { (Hsieh et al. 1996; } \\
\text { Parkin 2006) }\end{array}$ \\
\hline $\begin{array}{l}\text { HTLV- } \\
\quad 1\end{array}$ & Adult T-cell leukemia & 0.3 & $\begin{array}{l}\text { Direct carcinogens act via } \\
\text { expression of viral } \\
\text { oncoproteins }\end{array}$ & $\begin{array}{c}\text { (Jeang 2010; Parkin } \\
\text { 2006) }\end{array}$ \\
\hline KSHV & $\begin{array}{l}\text { Kaposi's sarcoma and primary effusion } \\
\text { lymphoma }\end{array}$ & 1 & $\begin{array}{l}\text { Direct carcinogens act via } \\
\text { expression of viral } \\
\text { oncoproteins }\end{array}$ & $\begin{array}{l}\text { (Parkin 2006; zur } \\
\text { Hausen 2001) }\end{array}$ \\
\hline $\mathrm{MCV}$ & Merkel cell carcinoma & NA & $\begin{array}{l}\text { Direct carcinogens act via } \\
\text { expression of viral } \\
\text { oncoproteins } \\
\end{array}$ & (Parkin 2006) \\
\hline
\end{tabular}

2 
Table 2 (on next page)

Summary of the VLP based cancer vaccines 
1 Table 2: Summary of the VLP based cancer vaccines

\begin{tabular}{|c|c|c|c|c|c|}
\hline No. & VLPs & Cancer antigen targeted & $\begin{array}{c}\text { Viral antigen } \\
\text { targeted }\end{array}$ & $\begin{array}{l}\text { Types of } \\
\text { vaccines }\end{array}$ & Reference \\
\hline \multicolumn{6}{|c|}{ Viral Like Particles and Hepatocellular Carcinoma } \\
\hline 1 & Hamster polyomavirus & - & HBsAg & Therapeutic & (Pleckaityte et al. 2015) \\
\hline 2 & $\begin{array}{l}\text { Macrobrachium } \\
\text { rosenbergii nodavirus }\end{array}$ & - & 'a' determinant & Preventive & (Yong et al. 2015) \\
\hline 3 & HBsAg & - & HVR1 & Preventive & (Vietheer et al. 2007) \\
\hline 4 & $\mathrm{HCV}$ & - & E1 and E2 & Preventive & (Elmowalid et al. 2007) \\
\hline 5 & Retrovirus & - & E1 and E2 & Preventive & (Garrone et al. 2011) \\
\hline 6 & $\mathrm{HBc}$ & MAGE-1 & - & Therapeutic & (Zhang et al. 2007) \\
\hline 7 & $\mathrm{HBc}$ & MAGE-3 & - & Therapeutic & (Zhang et al. 2007) \\
\hline 8 & HBc & AFP1 & - & Therapeutic & (Zhang et al. 2007) \\
\hline 9 & $\mathrm{HBc}$ & HBx & - & Therapeutic & (Ding et al. 2009) \\
\hline \multicolumn{6}{|c|}{ Virus Like Particles and HPV Associated Cervical Cancer } \\
\hline 1 & HPV & & L1 and L2 & Preventive & (Huber et al. 2015; Pineo et al. 2013) \\
\hline 2 & IBDV & E7 & & Therapeutic & (Martin Caballero et al. 2012) \\
\hline 3 & RHDV & E6 & & Therapeutic & (Jemon et al. 2013) \\
\hline \multicolumn{6}{|c|}{ Virus Like Particles and Pancreatic Cancer } \\
\hline 1 & SIV & Trop2 & & Therapeutic & (Cubas et al. 2011) \\
\hline 2 & SHIV & hMSLN & & Therapeutic & (Li et al. 2008) \\
\hline 3 & SHIV & mMSLN & & Therapeutic & (Zhang et al. 2013) \\
\hline \multicolumn{6}{|c|}{ Virus Like Particles and Prostate Cancer } \\
\hline 1 & Murine polyomavirus & PSA & & Preventive & (Eriksson et al. 2011) \\
\hline \multicolumn{6}{|c|}{ Virus Like Particles and Breast Cancer } \\
\hline 1 & Murine polyomavirus & Her2 & & $\begin{array}{l}\text { Therapeutic and } \\
\text { preventive }\end{array}$ & $\begin{array}{l}\text { (Tegerstedt et al. 2007; Tegerstedt et al. } \\
2005)\end{array}$ \\
\hline 2 & Influenza A virus & Her2 & & Preventive & (Patel et al. 2015) \\
\hline
\end{tabular}




\begin{tabular}{|l|l|l|l|l|l|}
\hline 1 & HBc & MAGE-3 & & Therapeutic & (Kazaks et al. 2008) \\
\hline 2 & Murine polyomavirus & OVA (model antigen) & & Therapeutic & (Brinkman et al. 2005) \\
\hline 3 & Murine polyomavirus & TRP2 & & Therapeutic & (Brinkman et al. 2005) \\
\hline 4 & RHDV & gp33 (model antigen) & & Preventive & (McKee et al. 2012) \\
\hline Virus Like Particles and Lung Cancer & CLDN18.2 & Preventive & (Klamp et al. 2011) \\
\hline 1 & HBc & & Preventive & (Ogembo et al. 2015) \\
\hline Virus Like Particles and EBV Associated Cancers & gp350/220 & Preventive & (Ruiss et al. 2011) \\
\hline 1 & NDV & & & \\
\hline 2 & EBV & &
\end{tabular}

